Tabales Rodríguez, M.A., Utrera Burgal, R., y Pajuelo Sáez, J.M. (2020): “La plataforma de cimentación de un templo romano en Oba (Jimena de la Frontera, Cádiz). Aproximación a su estudio", Spal 29.2: 109-127. DOI: https://dx.doi.org/10.12795/spal.2020.i29.20

\title{
LA PLATAFORMA DE CIMENTACIÓN DE UN TEMPLO ROMANO EN OBA (JIMENA DE LA FRONTERA, CÁDIZ). APROXIMACIÓN A SU ESTUDIO
}

\section{THE FOUNDATION PLATFORM OF A ROMAN TEMPLE IN THE ANCIENT CITY OF OBA (JIMENA DE LA FRONTERA, CÁDIZ). INITIAL STUDY}

\author{
MIGUEL ÁNGEL TABALES RODRÍGUEZ \\ Departamento de Construcciones Arquitectónicas II, Universidad de Sevilla, \\ Escuela Técnica Superior de Ingeniería de Edificación. Avda. Reina Mercedes s/n. D.P. 41012 Seville, Spain \\ Correo-e: tabales@us.es (D) https://orcid.org/0000-0002-9884-7407 \\ ResearcherID: https://publons.com/researcher/AAX-7229-2020 \\ RAQUEL UTRERA BURGAL \\ Responsable de la correspondencia \\ Arqueóloga. Licenciada en Historia por la Universidad de Cádiz. \\ Correo-e: raquel.utrera.b@gmail.com D https://orcid.org/0000-0001-5608-239X \\ ResearcherID: https://publons.com/researcher/AAX-3651-2020 \\ JUAN MIGUEL PAJUELO SÁEZ \\ Gerente TripMilenaria Museum Store. C/ San Antonio Abad no 2 local bajo, esquina con calle Mesón. D.P. 11005. Cádiz. \\ Correo-e: tripmilenaria@gmail.com D https://orcid.org/0000-0001-9034-6088 \\ ResearcherID: https://publons.com/researcher/AAX-4288-2020
}

Resumen: En este artículo presentamos un análisis preliminar de la plataforma de cimentación de un templo, cuyas dimensiones y sistema constructivo es fundamental para acercarnos a la arquitectura de la Hispania romana. Las conclusiones expuestas son el resultado de varias campañas arqueológicas de apoyo a la restauración en el yacimiento conocido como castillo de Jimena, la antigua $O b a$, donde se sitúa el origen de la ciudad. En la zona del templo y sus alrededores se realizaron varias intervenciones arqueológicas de subsuelo, junto a un análisis previo de la estructura emergente, siguiendo la metodología habitual de nuestras intervenciones (Tabales Rodríguez 2002). La investigación ha puesto en evidencia la complejidad constructiva del asentamiento desde época romana hasta las últimas reformas en la Guerra de la Independencia. La plataforma abovedada destaca dentro del conjunto por su tamaño y características edilicias. Su ubicación, en una terraza artificial abovedada en la ladera occidental, conllevó un gran esfuerzo constructivo inserto en un planeamiento general de urbanización de espacios públicos y amurallamiento de la pequeña población, que se llevó a cabo entre el siglo I a. C. y siglo I d. C., indicando el inicio del momento de máximo esplendor de la presencia romana en la zona.

Palabras clave: Arqueología de la arquitectura, restauración de edificios históricos, arquitectura romana, arquitectura sagrada, Baetica.
Abstract: We present an initial study based on a foundation platform of a temple, which due to its size and construction system, is a key to approach the architecture of the Roman Spain. Conclusions exposed are the result of several archaeological campaigns supporting the restoration at the site known as castle of Jimena, old Oba, where the origin of the village is situated. Some archaeological excavations and an initial analysis of the construction process were accomplished in the surrounding area, following the usual methodology in our investigations (Tabales Rodríguez 2002). This has exposed the construction complexity of the settlement since the roman days to the last reforms carried out during the War of Independence. The vaulted platform is one of the structures that stand out from the complex because of its size and building characteristics. Its location, at a vaulted artificial terrace on the western slope, involved a great constructive effort included in a general urban planning of public areas and the fortress of the small village that was carried out during the 1st century B.C. and the 1st century A.D., which marks the beginning of the roman golden age in that area.

Keywords: Archaeology of architecture, restoration of historic buildings, Ancient Roman architecture, sacral architecture, Baetica. 


\section{INTRODUCCIÓN}

Jimena de la Frontera es una población situada en la provincia de Cádiz, al sur de España, en la comarca del Campo de Gibraltar. El término municipal se encuentra en su mayor parte dentro del entorno del Parque Natural de los Alcornocales y destaca por su riqueza arqueológica, con multitud de yacimientos documentados desde la prehistoria hasta época medieval (García Díaz et al. 2003).

La antigua ciudad de $O b a$ se ubica en el conocido como cerro del Castillo o cerro de San Cristóbal, al oeste de la población actual. La ocupación de este promontorio se constata desde fechas muy tempranas, así destacan la serie de abrigos denominados "Cuevas de la Chinchilla", muy próximos a la fortaleza, en los que se representaron pinturas rupestres, algunas de ellas actualmente desaparecidas. Las intervenciones arqueológicas realizadas en el castillo por este equipo, desde los años 2002 a 2012 (Reina y Tabales 2006) han puesto de manifiesto una ocupación prolongada, con materiales desde el Bronce Final (Huarte Cambra 2005: 125) hasta las reformas realizadas en sus murallas en el siglo XIX, con motivo de la Guerra de la Independencia.

El topónimo de la ciudad se conocía gracias a la aparición de monedas bilingües con caracteres latinos y libio-fenicios, acuñaciones que se fechan en el siglo I a.C. (Villaronga 1994: 127 y 128). Su posible origen libio-púnico se relaciona con la gran abundancia de las formas $O B A / U B A$ en la órbita norteafricana de Cartago (Carretero Poblete 2008: 1335). Por inscripciones de la época (CIL II 1330 y 1334, IRPCA números 523 y 527, Romero de Torres, 1934: 208-209, Regueira et al. 1988: 62 y 64) sabemos que el nombre se latinizó tras la conquista romana, pasando a denominarse Respublica Obensis, que gozó del estatuto de municipio de derecho latino durante el gobierno de Vespasiano, 69-79 d.C.

El actual nombre de la población proviene del topónimo islámico SHEMINA, que aparece por primera vez en el Rawd-al-Kirtas de Ibn Abi Zar, dentro de las fortificaciones entregadas por el sultán merinita Abu Ya'qub al rey de Granada Muhammad II en 1293 (Regueira et al. 1988: 82). Son numerosas las construcciones que reflejan la presencia islámica en la fortaleza, destacando el acceso al recinto, la llamada Puerta del Reloj o el aljibe almohade. La definitiva conquista cristiana se produjo en 1451, a partir de esas fechas comenzó la desaparición de la frontera (Regueira et al. 1988: 121) y el crecimiento poco a poco de la población extramuros, hacia la ladera oriental, lugar donde se ubica actualmente la ciudad.

\section{ANTECEDENTES}

La construcción que nos ocupa se encuentra en la ladera occidental del castillo (fig. 1). A simple vista, se destacan una serie de bóvedas parcialmente conservadas que soportan una terraza destruida. Debido a su monumentalidad y a su posición, sobresaliendo de la muralla, es una de las estructuras que debieron distinguirse siempre en el cerro. Sin embargo las primeras referencias especializadas no aparecieron hasta el año 2001, cuando Hamo Sassoon realizó una descripción de la misma, señalando su origen romano y su finalidad como cimentación para sustentar algún edificio monumental, proyecto que según el autor, no debió concluirse debido a los pocos restos arquitectónicos localizados hasta esas fechas en el yacimiento (Hamo Sassoon, 2001: 142 y 143). También indicó la posibilidad de que los llamados "pozos" de la estructura fueran utilizados para almacenar cereal (Hamo Sassoon, 2001: 143).

A partir del año 2002, con motivo de la puesta en valor del castillo, comenzaron una serie de campañas arqueológicas de "apoyo a la restauración", en total seis hasta la fecha, cuyo principal objetivo era la restauración y el posterior uso público (Tabales y Reina, 2006: 154). Fue en la primera fase cuando se produjo un estudio general de toda la fortaleza, aplicando nuestra metodología habitual de aproximación a edificios históricos (Tabales Rodríguez, 2002), mediante un análisis de alzados de las estructuras emergentes junto a varios sondeos y limpiezas arqueológicas en diferentes zonas, destacando los realizados en la plataforma abovedada. El resultado (figs. 2 y 3 ) fue la identificación de cuatro grandes sistemas amurallados en el yacimiento -muralla romana, muralla islámica, reformas cristianas y reformas durante la Guerra de la Independencia-, destacando hasta tres fases durante el período romano (Tabales Rodríguez et al. 2002: 151-154, Tabales Rodríguez 2006: 27-29).

Gracias a estas intervenciones sabemos que la ciudad romana se originó sobre un asentamiento anterior, que conocemos únicamente por la gran cantidad de materiales cerámicos registrados del horizonte prerromano (Huarte Cambra 2005: 120-121), ya que no se han documentado hasta ahora estructuras asociadas. Presentaba un modelo urbano avanzado con una muralla que lo rodeaba ya en época altoimperial (Tabales Rodríguez 2006: 27 y 28) y la presencia de al menos dos puertas. La primera de ellas, estaba emplazada en la ladera occidental hacia el río Hozgarganta, cercana a la plataforma, de la que se documentó en la actuación 
del año 2007 una jamba y un gran escalón de caliza excavado en la roca natural. La otra, se situaría posiblemente en el lugar en el que se erigió el acceso de época islámica, en la ladera oriental (Tabales Rodríguez 2006: 29), orientada a la campiña del río Guadiaro, donde existió una enorme actividad agrícola e importancia económica en la época tal y como lo atestiguan la multitud de villas en torno al río registradas en las campañas de prospección realizadas en la zona (García Díaz et al. 2003).

Con respecto al trazado urbano del interior de la ciudad, se tienen escasos datos, ya que las campañas realizadas hasta la fecha se han ubicado en zonas concretas con un enorme potencial de cara a su restauración y posterior uso público (Reina y Tabales 2006). Por otro lado, en las zonas en las que se ha podido intervenir, la potencia del registro arqueológico ha dificultado el acceso a las etapas más antiguas de la ocupación del yacimiento. No obstante, se ha documentado la presencia de estructuras relacionadas con sistemas de aprovisionamiento como varias cisternas o un silo, destacando la aparición de una edificación monumental en la ladera oriental, situada paralelamente al edificio objeto de este estudio, lo que implica un planeamiento en la construcción de los edificios públicos.

En época bajoimperial se produjo un refuerzo de las defensas de la ciudad, en algunas zonas fortificando la muralla anterior y en otras sustituyéndola por una cerca más defensiva y añadiendo nuevos elementos como un gran bastión que haría más inaccesible la puerta occidental, que también se transformó (Tabales Rodríguez et alii 2002: 15-154). De estos momentos se conserva, próxima a la muralla oriental, parte de una calzada que recorre más de siete metros, formada por losas calizas pulimentadas de corte irregular (Tabales Rodríguez et al. 2002: 140).

Las bóvedas de la ladera occidental se interpretaron tras la primera intervención como la base de un templo tetrástilo próstilo, completamente desaparecido, muy similar a los tres templos adscritos tradicionalmente a la tríada capitolina (Sillières 1997: 87-95) en la cercana ciudad de Baelo Claudia (Tabales Rodríguez 2006: 10).

En las campañas de los años 2005 y 2007, se realizaron por un lado, la excavación de varias de las bóvedas de la plataforma hasta llegar a la roca natural en la que se asienta, con el fin de obtener una secuencia estratigráfica completa y determinar si la estructura de sustentación tuvo algún otro uso; y por otro, la limpieza del entorno inmediato a la plataforma (figs. 4 y 5) para hacerla accesible, ya que en esas fechas

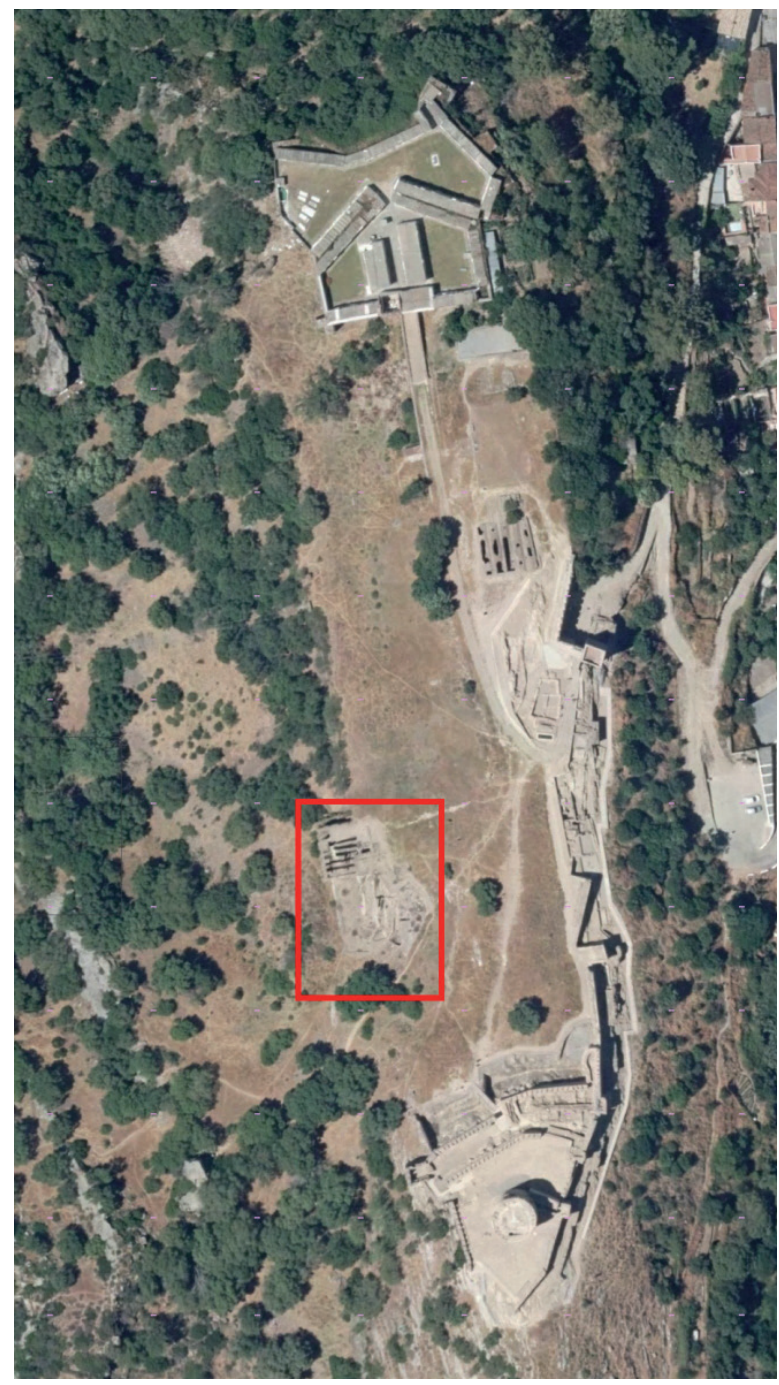

Figura 1. Fotografía aérea del castillo de Jimena de la Frontera, antigua $O b a$, con zona de ubicación de la plataforma.

era prácticamente intransitable debido a la pendiente pronunciada y a la cantidad de material de derrumbe acumulado.

\section{DESCRIPCIÓN}

La ladera del castillo en que se ubica la construcción se orienta actualmente hacia el Parque Natural de los Alcornocales y el río Hozgarganta, muy cercano y que ha sido el recurso fundamental de agua dulce de la población desde la Antigüedad. La plataforma abovedada se planteó como un cubo de gran tamaño, que sobresalía de la alineación de la muralla romana en el frente 


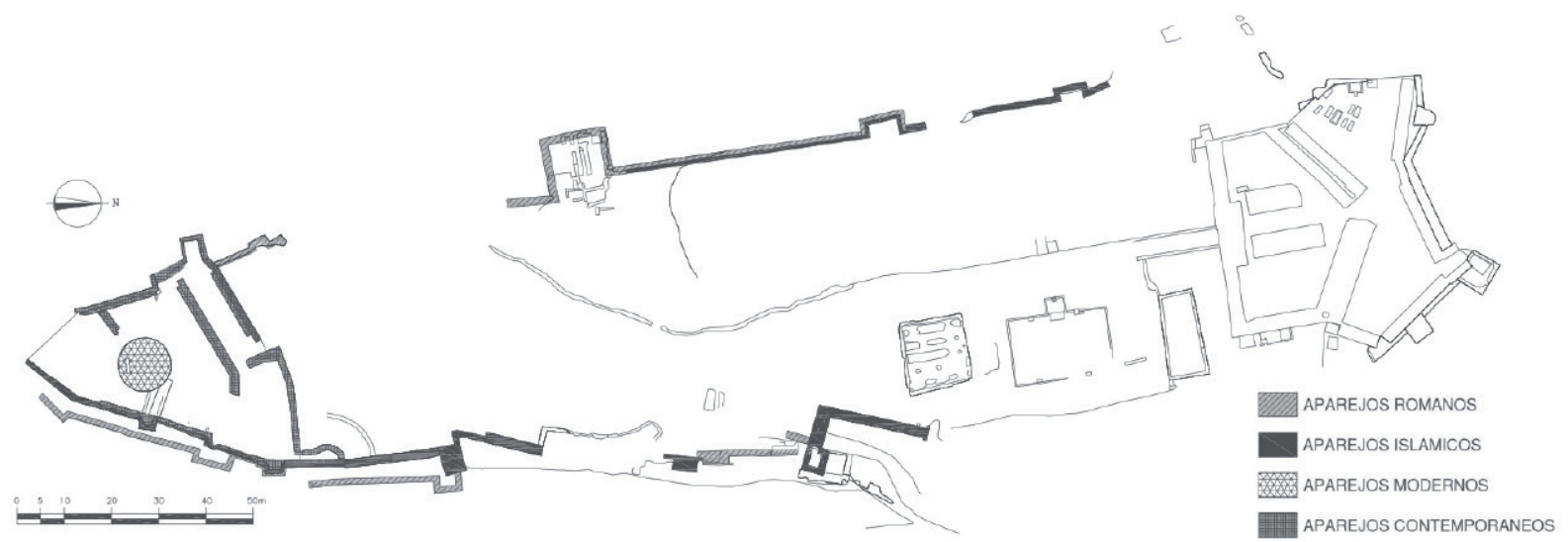

Figura. 2. Plano del castillo con el resultado del estudio paramental efectuado en el año 2002.

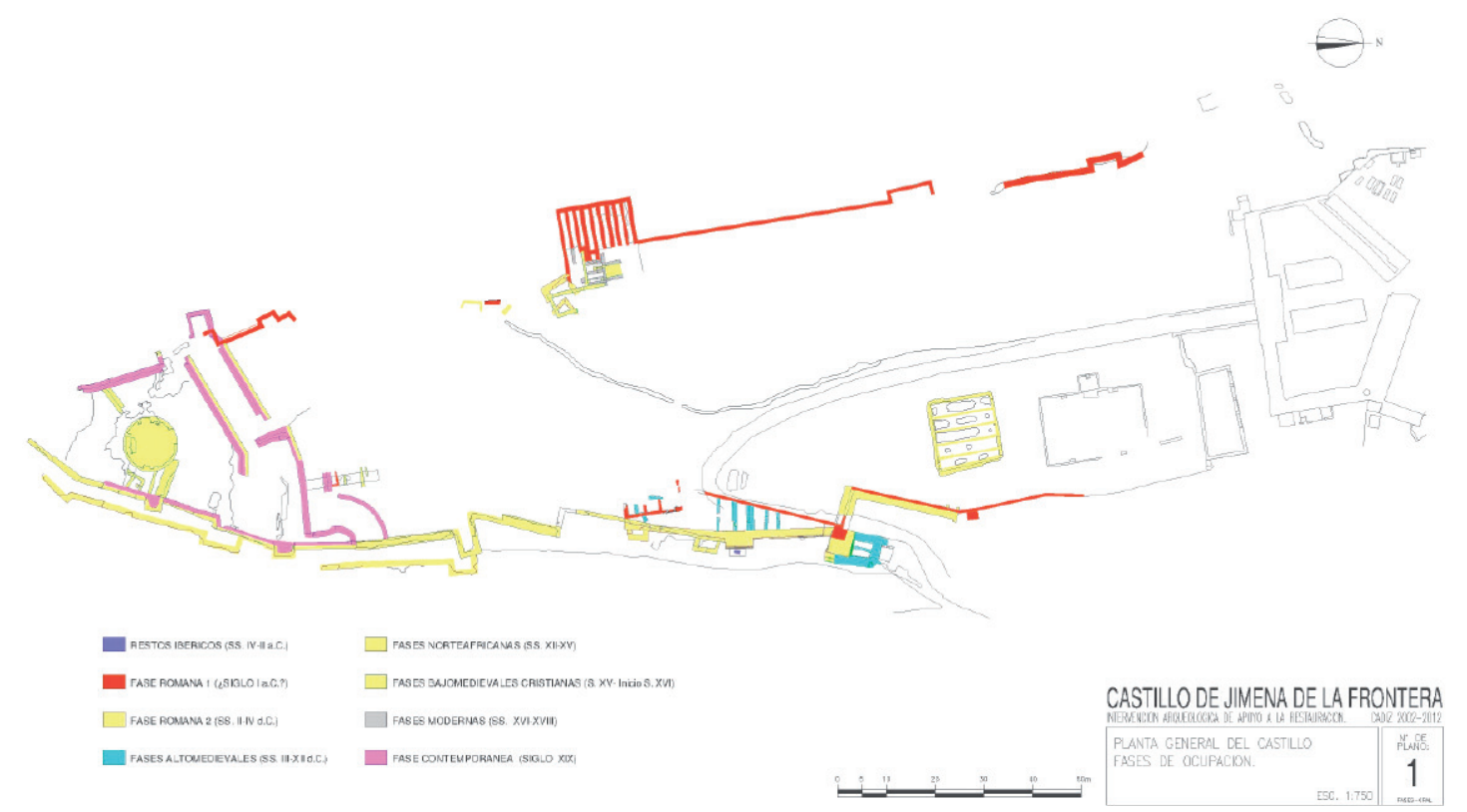

Figura 3 Plano del castillo con evolución de etapas constructivas resultado del estudio paramental efectuado en el año 2002 y edificación localizada en el año 2012.

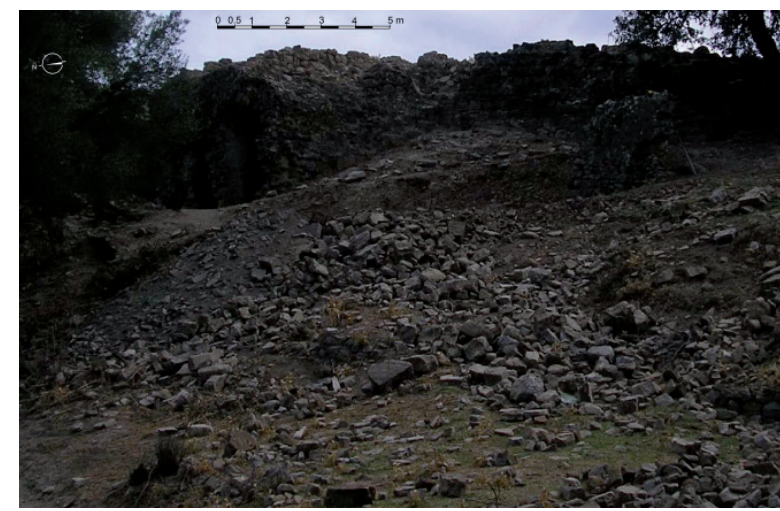

Figura 4. Detalle de la zona antes del inicio de las intervenciones de limpieza.

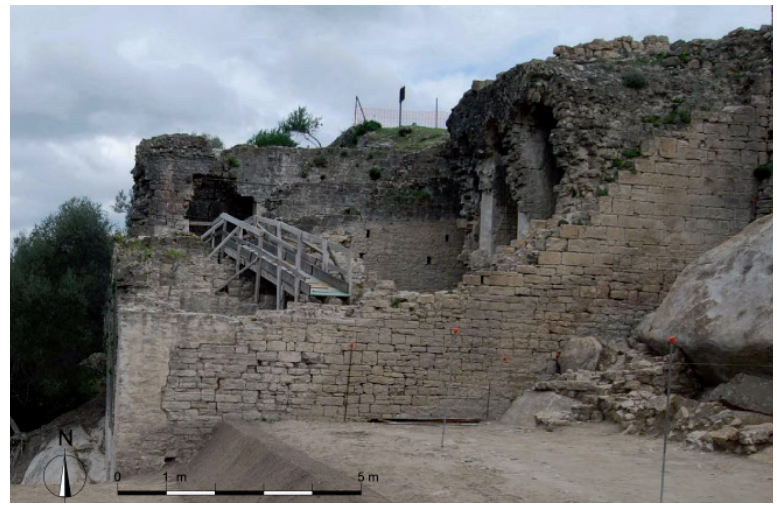

Figura 5. Frente meridional de la plataforma, una vez terminados los trabajos.

ISSN: 1133-4525 ISSN-e: 2255-3924 https://dx.doi.org/10.12795/spal.2020.i29.20 
occidental. Su ubicación está relacionada con la cercanía a una de las puertas de la ciudad que se abría en esta ladera.

Al sur, se le adosó entre los siglos II-III d.C. un torreón de grandes dimensiones. Al norte colinda con la muralla, que en su parte inferior claramente se adosa a la plataforma (fig. 6). Sin embargo, a partir de una altura cercana a la imposta de la bóveda septentrional, se produce un encastre de las dos estructuras de manera que, aunque constructivamente la plataforma empezó a edificarse primero, ambas forman parte del mismo proceso de urbanización de la ciudad. El aparejo de las dos construcciones es similar, aunque con una mayor calidad en la plataforma (fig. 7), configurándose como una fábrica de tres hojas de mampuestos y sillarejos de piedra caliza tallados regularmente y bien escuadrados, tendencia a la horizontalidad y adecuación de piezas, con algunas cuñas también escuadradas. El revestimiento se une a hueso por el exterior, mientras que se emplea argamasa en el interior. En la muralla se identifica una fábrica también de tres hojas con revestimiento de sillarejos pseudoisódomos tendentes a la soga, a hueso o trabados con fina argamasa y con finas cuñas de nivelación. Ambas fueron datadas en la primera intervención en torno al siglo I a.C. (Tabales Rodríguez et al. 2005: 141) y en ellas se observa una vinculación entre las tendencias constructivas romanas, representadas por el uso del aparejo de calidad, y la tradición púnica, representada por la tendencia a la horizontalidad combinada con bloques de distinto tamaño.

La plataforma es de forma rectangular, aunque sus medidas no son homogéneas, ya que se fue adaptando a las curvas naturales del terreno de la ladera, buscando la cimentación en la roca natural arenisca de la zona (figs.8 y 9). En el interior y en su esquina septentrional se puede apreciar cómo en algunas zonas la roca madre fue acondicionada y tallada para facilitar la cimentación y el paso durante los trabajos de construcción (fig. 10).

En lo que concierne al alzado, los muros y bóvedas interiores alcanzaron más altura a medida que se fueron alejando de la terraza natural, siempre buscando la cimentación en la base geológica del terreno, que tiene una considerable pendiente, llegando a visualizarse hoy desde el exterior una altura de casi $10.5 \mathrm{~m}$.

La estructura interna está formada por una serie de pasillos o galerías (figs. 11 y 12), cuyos lienzos parten de la zona oriental de la ladera, alcanzando mayor longitud en función de la aparición de la roca natural, de tal forma que aunque en el exterior se nos presenta como una edificación más pequeña, en el interior se observan

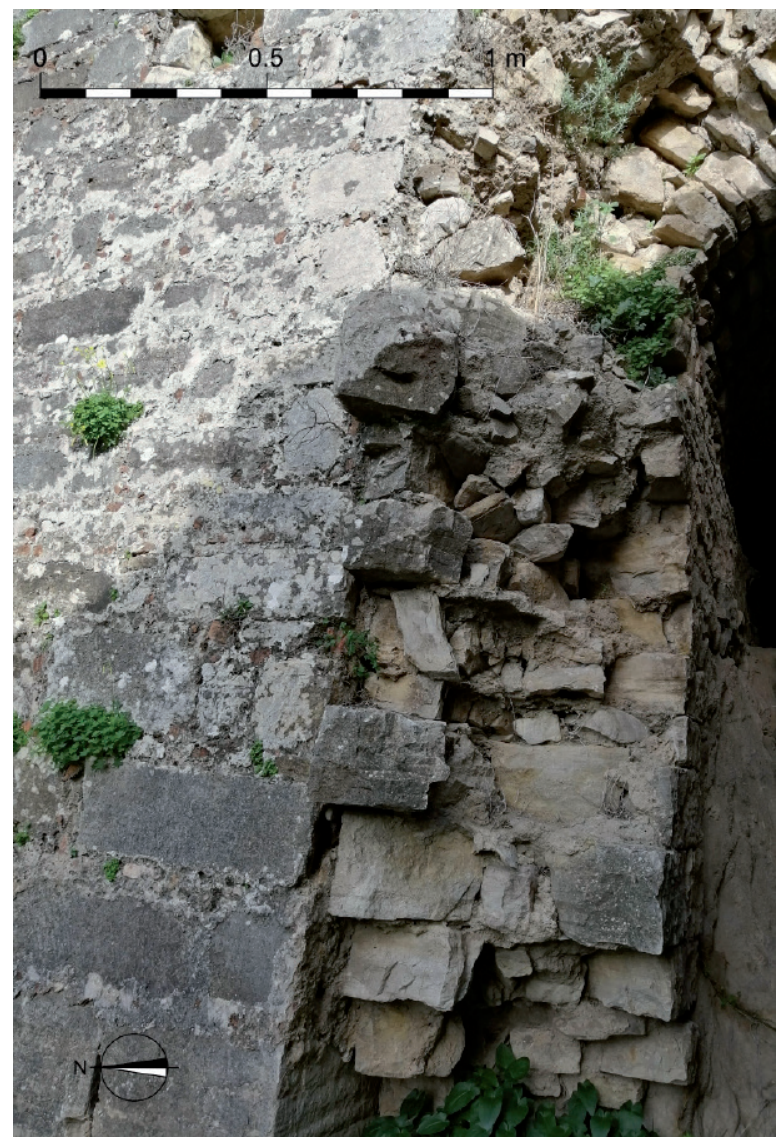

Figura 6. Detalle del contacto entre muralla y plataforma al norte.

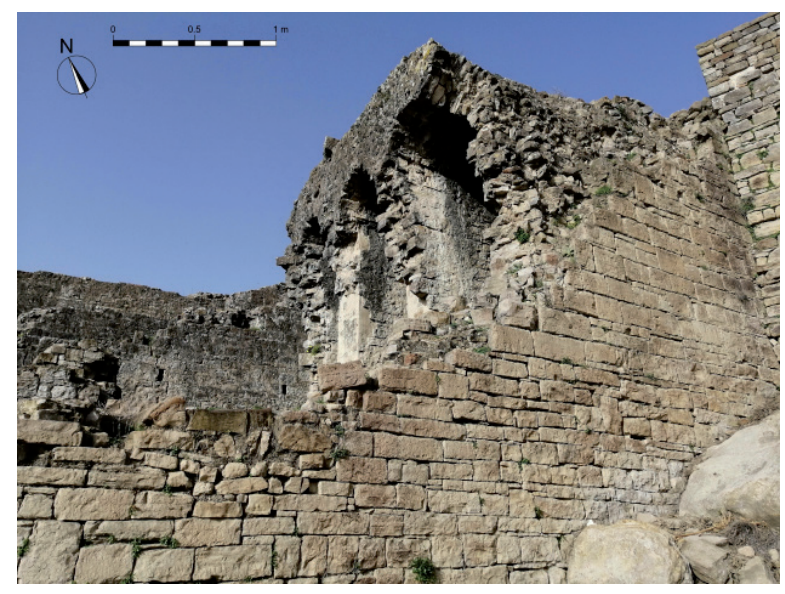

Figura 7. Detalle del aparejo de la fachada meridional de la plataforma.

sus dimensiones reales, penetrando en la ladera como galerías subterráneas. Con respecto a sus muros perimetrales, su lienzo occidental mide $15.48 \mathrm{~m}$ de longitud y por el exterior los laterales alcanzan al norte 


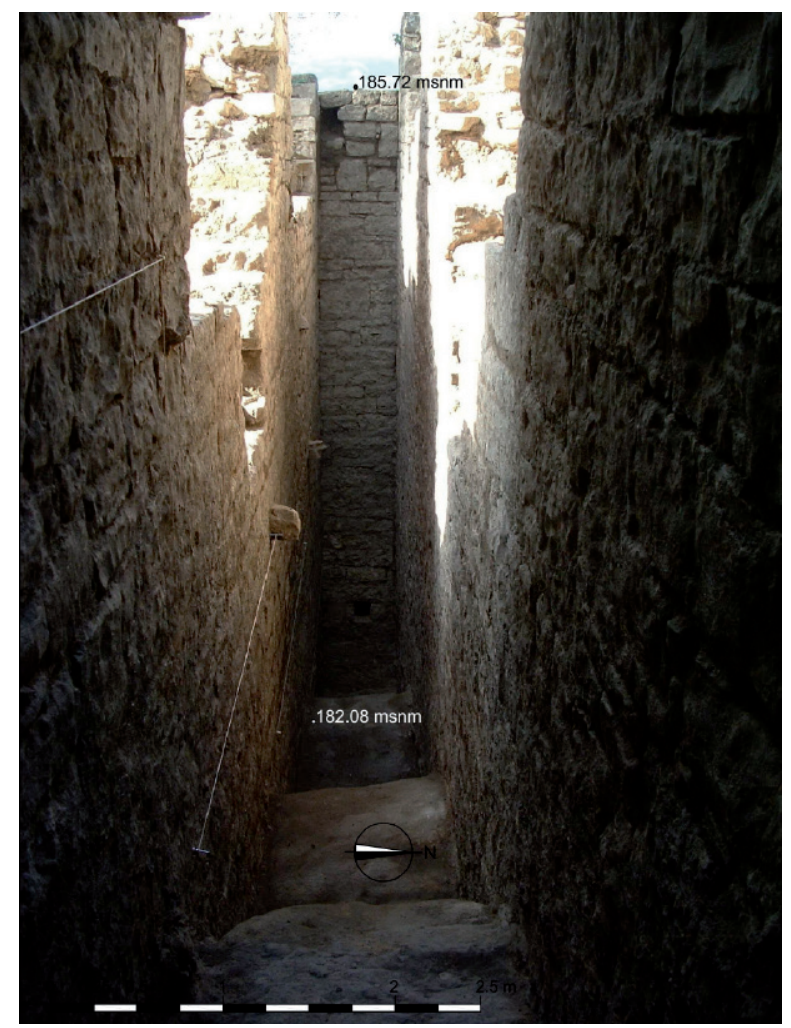

Figura 8. Imagen de una de las divisiones internas de la plataforma tras finalizar su excavación. Nótese como los lienzos se apoyan en la roca natural siguiendo la pendiente natural del terreno.

unos $8.90 \mathrm{~m}$ hasta la muralla, y $16.86 \mathrm{~m}$ al sur, hasta el bastión del siglo III d.C. Sin embargo, por el interior la galería más septentrional -galería 9- alcanza $18.70 \mathrm{~m}$ desde su inicio hasta la cara externa de la fachada occidental; la más meridional tiene $17.21 \mathrm{~m}$ de longitud galería $1-$, siendo la galería más larga la segunda desde el norte -galería 8-, con más de $21 \mathrm{~m}$.

Las bóvedas son de medio punto con tendencia a peraltadas (fig. 13), con dovelas de piedra y fueron realizadas con cimbras, cuyas huellas han quedado marcadas en alguna de ellas (fig. 14). La luz de los arcos varía entre los $0.69 \mathrm{~m}$ a $1.02 \mathrm{~m}$, en función de la anchura del pasillo, y la flecha medida en la galería 9 tiene $0.7 \mathrm{~m}$ (por 1.01 de luz). La excavación de algunos de esos tramos nos ha permitido conocer que la altura máxima desde la roca hasta la clave de las bóvedas alcanza unos 9.8 metros. No obstante, a medida que nos acercamos a los extremos orientales de los que arrancan esas cimentaciones, las alturas van disminuyendo y el interior de algunos de estos pasillos es prácticamente inaccesible. En la galería septentrional, se observa cómo la altura de la roca coincide con la imposta de la bóveda, por lo que en estos tramos más angostos, la roca debió servir de base del apoyo de la cimbra.

Existe una diferenciación entre los tres tramos centrales de la edificación y las galerías laterales, así estas últimas tanto al norte como al sur están abovedadas completamente y son continuas, diáfanas y sin interrupciones - galerías 1 a 3 y 7 a 9-. Sin embargo, los tres tramos centrales se encuentran compartimentados con una serie de muros perpendiculares a su trazado, siendo el situado más al sur -4-, donde se han registrado los tres lienzos que dividen el espacio en cuatro, de tal forma que a su extremo más oriental (fig. 15) solo se puede acceder desde la galería lateral -3-, a través de una ruptura posterior en unos de sus muros. Las otras dos -5 y 6-, deben tener la misma compartimentación, aunque los tramos más orientales no se han podido documentar, pues sus muros se han mantenido intactos y no es posible acceder a ellas desde el interior. Estos tramos, por tanto, están completamente soterrados, y permanecen bajo los restos de edificaciones posteriores. Su existencia nos lleva a la conclusión de que esta plataforma no tuvo más fin que el de servir de sustentación y que estas galerías no estuvieron comunicadas en origen. La comunicación actual es resultado de rupturas que se hicieron posteriormente en los lienzos, destacando incluso la apertura de vanos de paso en las más septentrionales. Sin embargo, las cotas de uso y las huellas de ruptura en su realización nos indican que no son originales.

Con base en los restos conservados, las tres galerías centrales mantenían bóvedas a la altura del resto de la edificación tan solo en sus compartimentaciones más occidentales y orientales -galerías 10, 11, 12 y 14-(fig. 16). No se conoce cubrición en los espacios centrales de estas tres galerías -galerías 4, 5, 6 y 13-, sin embargo sus lienzos se alzan por encima del trazado de las bóvedas de la plataforma (fig. 17), lo que nos lleva a deducir que por un lado la cubrición, plana o abovedada, debió estar más elevada; y por otro y más importante, esta zona de la estructura destacaba en altura sobre el resto de la plataforma.

\section{PROCESO CONSTRUCTIVO E HIPÓTESIS FINAL}

Aunque no se ha realizado un estudio paramental específico y completo de la plataforma, durante el desarrollo de los trabajos se han podido documentar muchas de las relaciones entre sus lienzos lo que nos ha permitido acercarnos un poco a su proceso constructivo (fig. 18). 
$\mathrm{E}$

0

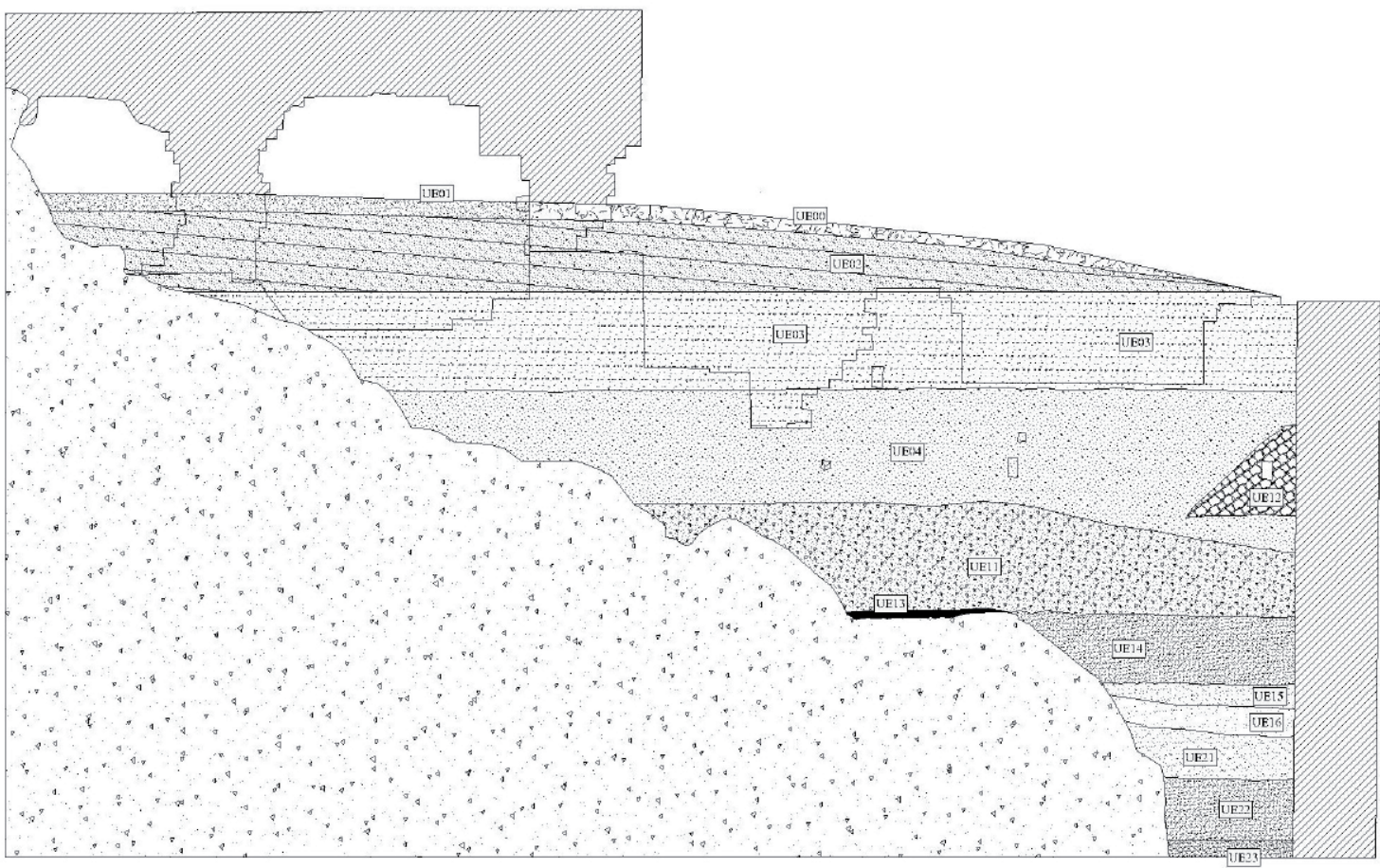

Figura 9. Perfil de la galería 3 con estratigrafía de los rellenos de colmatación. Obsérvese la disposición de la roca natural en pendiente.

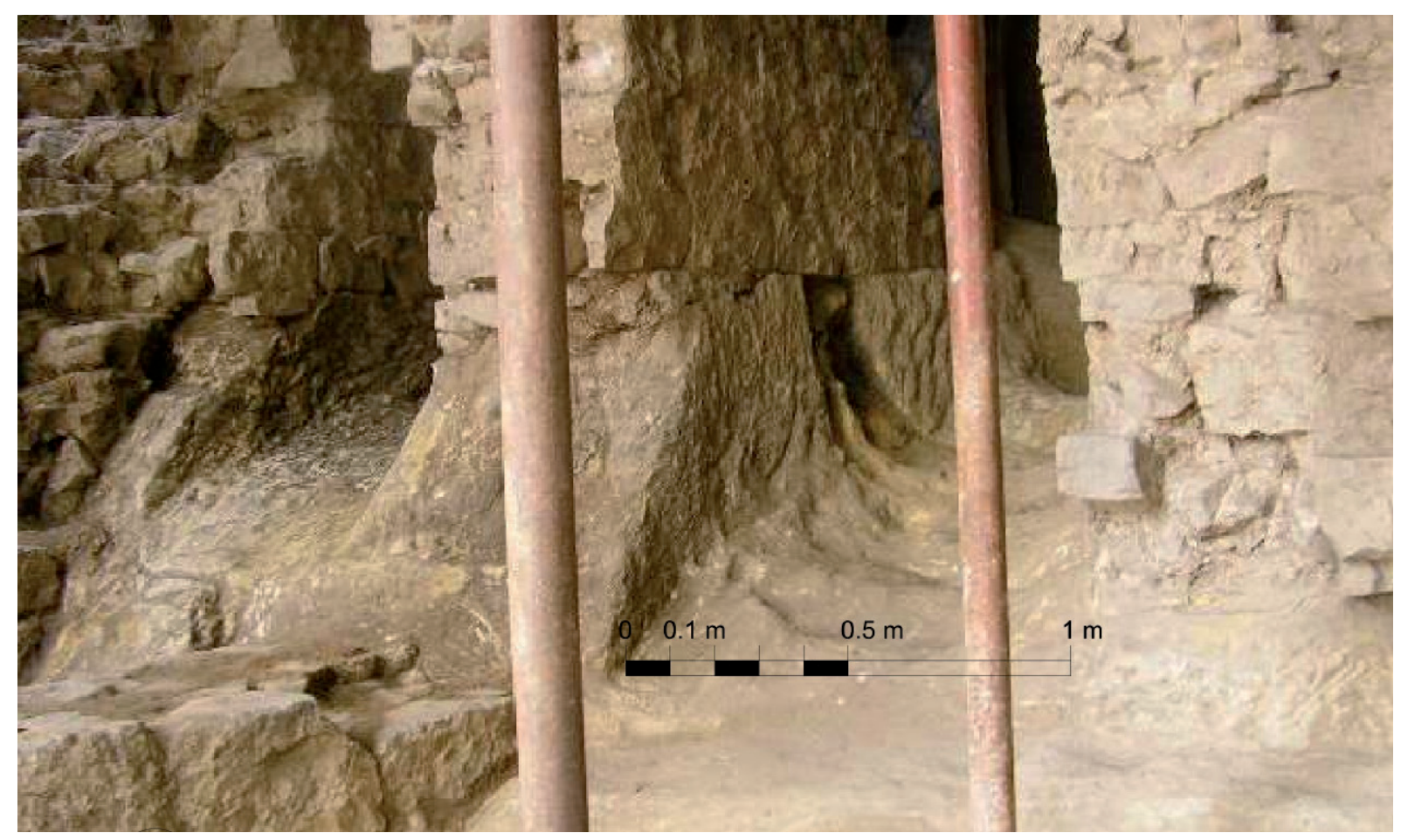

Figura 10. Detalle del proceso de talla de la roca natural para apoyar los lienzos y facilitar el paso.

ISSN: 1133-4525 ISSN-e: 2255-3924 


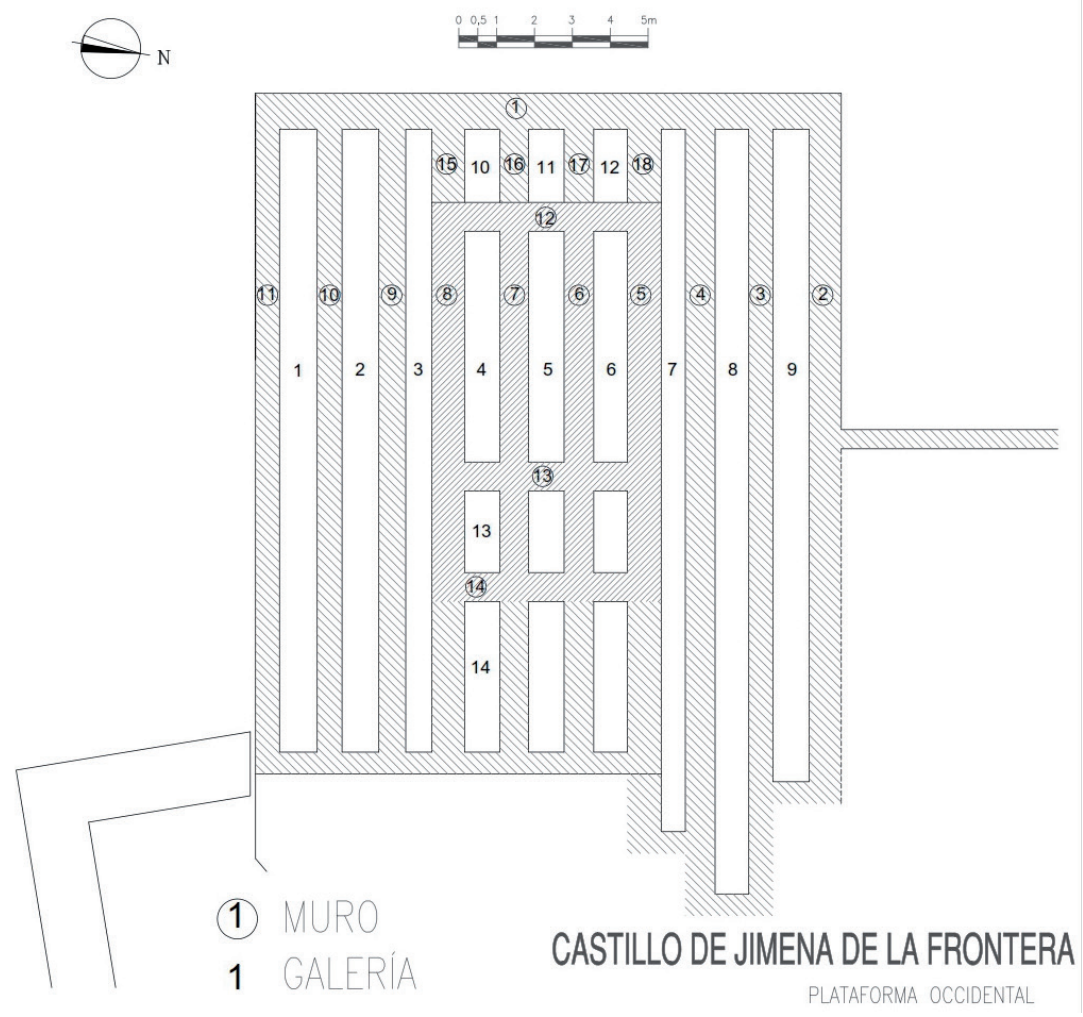

Figura 11. Planta de la edificación con identificación de muros y galerías.
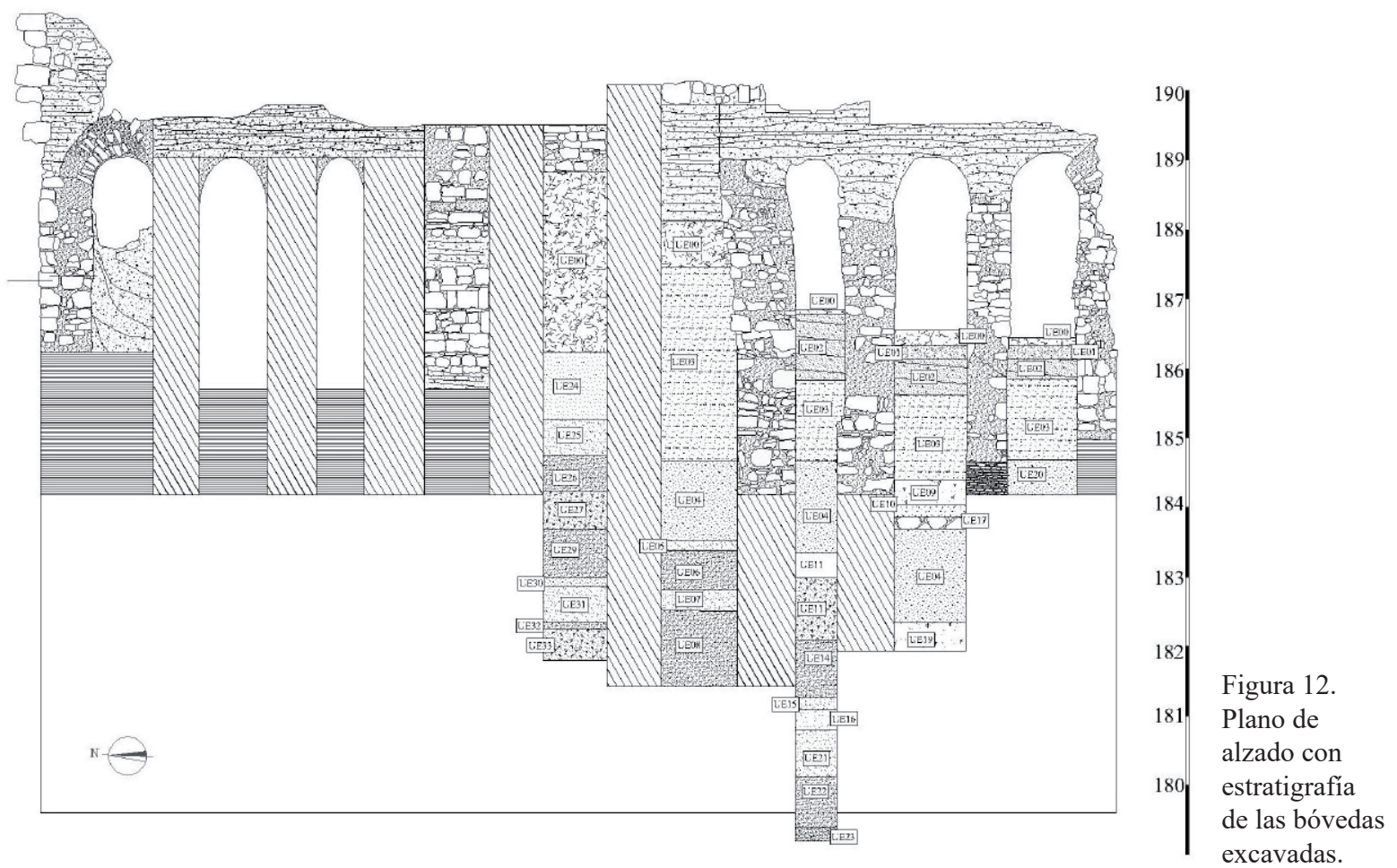


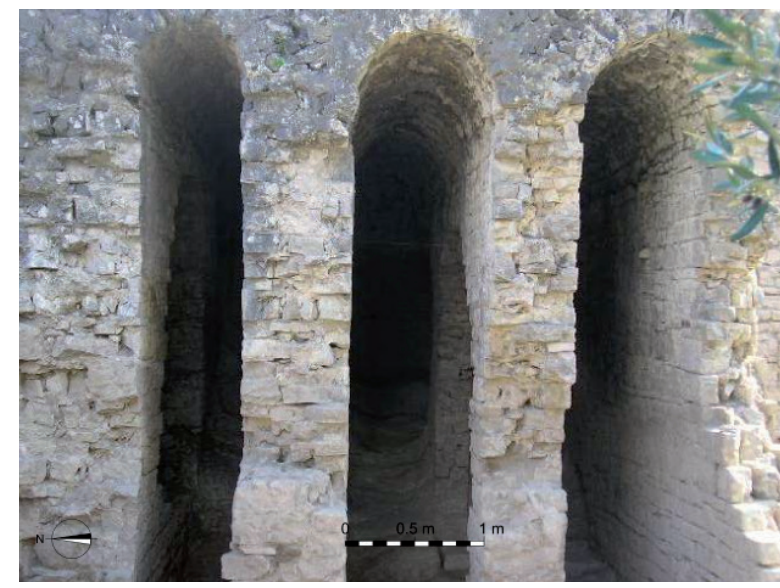

Figura 13. Imagen de las tres bóvedas de cañón meridionales.

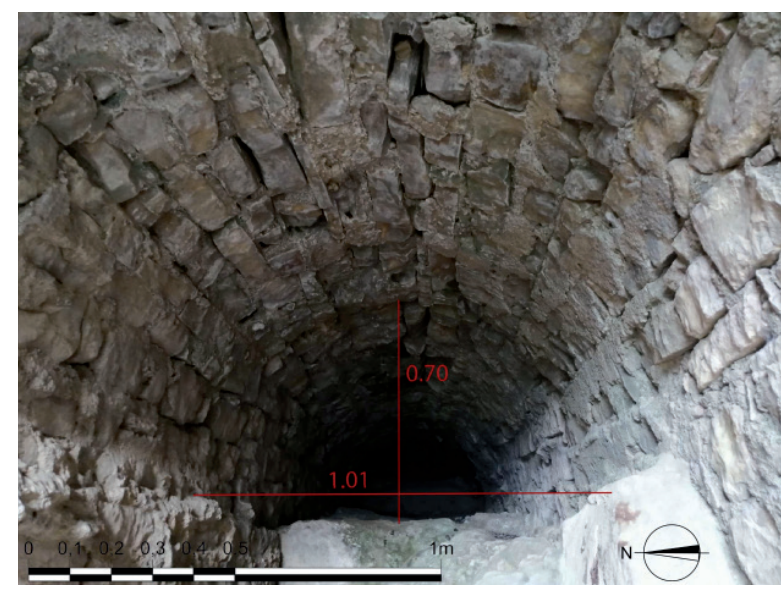

Figura 14. Detalle del interior de la galería septentrional. Obsérvense las huellas del encaje de la cimbra y cómo coincide la línea de imposta con la roca natural.

Como hemos visto anteriormente, existe una diferenciación entre las galerías centrales y las laterales, que tiene que ver claramente con la sustentación de la edificación superior. Este fue el fin de la estructura y también su inicio, de tal forma que en una primera fase, se comenzarían a construir los muros de las tres galerías intermedias, con el arranque en la falda del cerro, de este a oeste. Los muros de las galerías centrales y los muros perpendiculares se encuentran trabados y son claramente coetáneos (fig. 19). En cuanto a sus medidas, el ancho de los muros exteriores es de tres pies romanos $-0.88 \mathrm{~m}-\mathrm{y}$ la luz de las tres galerías son muy semejantes, entre los $0.9 \mathrm{~m}$ y $0.95 \mathrm{~m}$.

Una vez elevados las alineaciones que constituían la cimentación o entibo de la edificación central, se iniciaría la construcción de los lienzos perimetrales y de

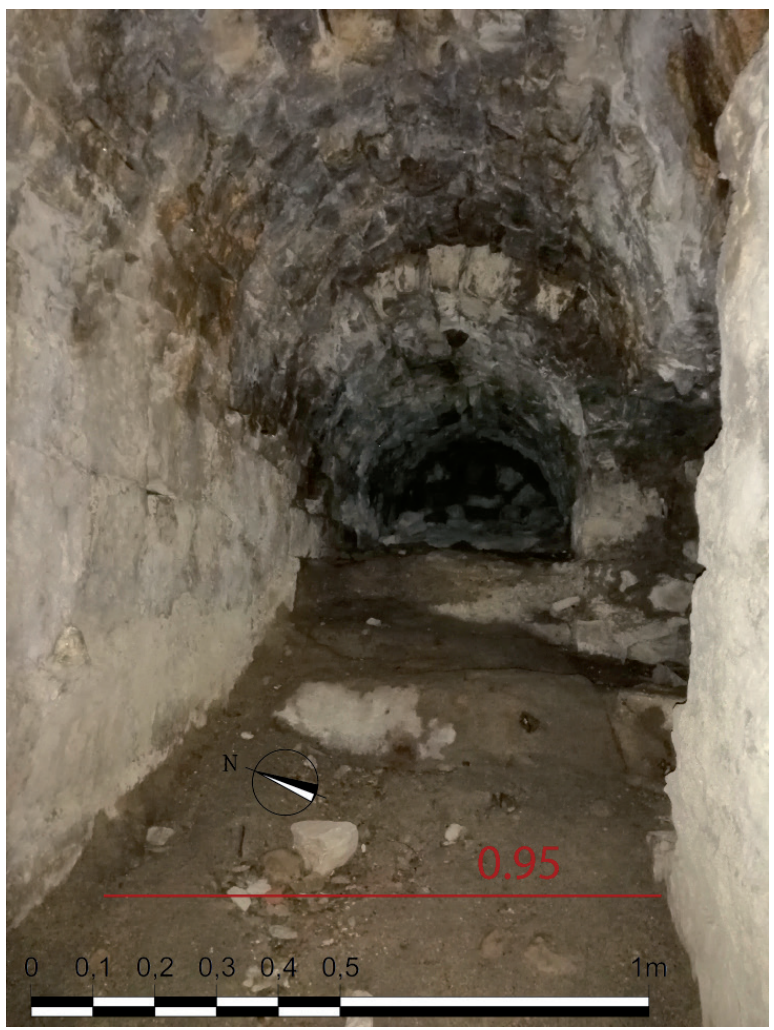

Figura 15. Interior del tramo más oriental de una de las bóvedas centrales.

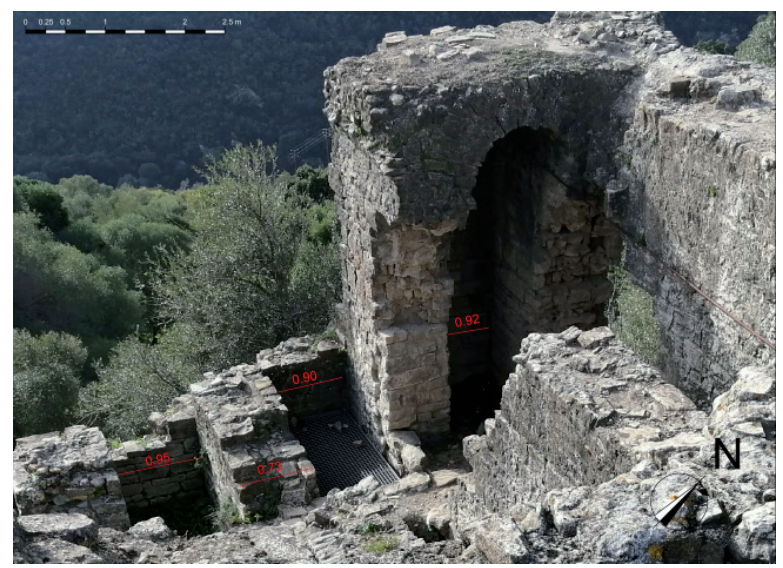

Figura 16. Detalle de los tres tramos centrales al oeste. Se puede observar cómo se conserva la bóveda más septentrional y el arranque de la central.

las galerías laterales, partiendo también desde la zona oriental. La unión de la fachada occidental con la zona central se realizó con pequeños muros trabados -15 a $18-$, que seguían el mismo trazado de los que conformaban las galerías centrales (fig. 19). Estos se adosaron 


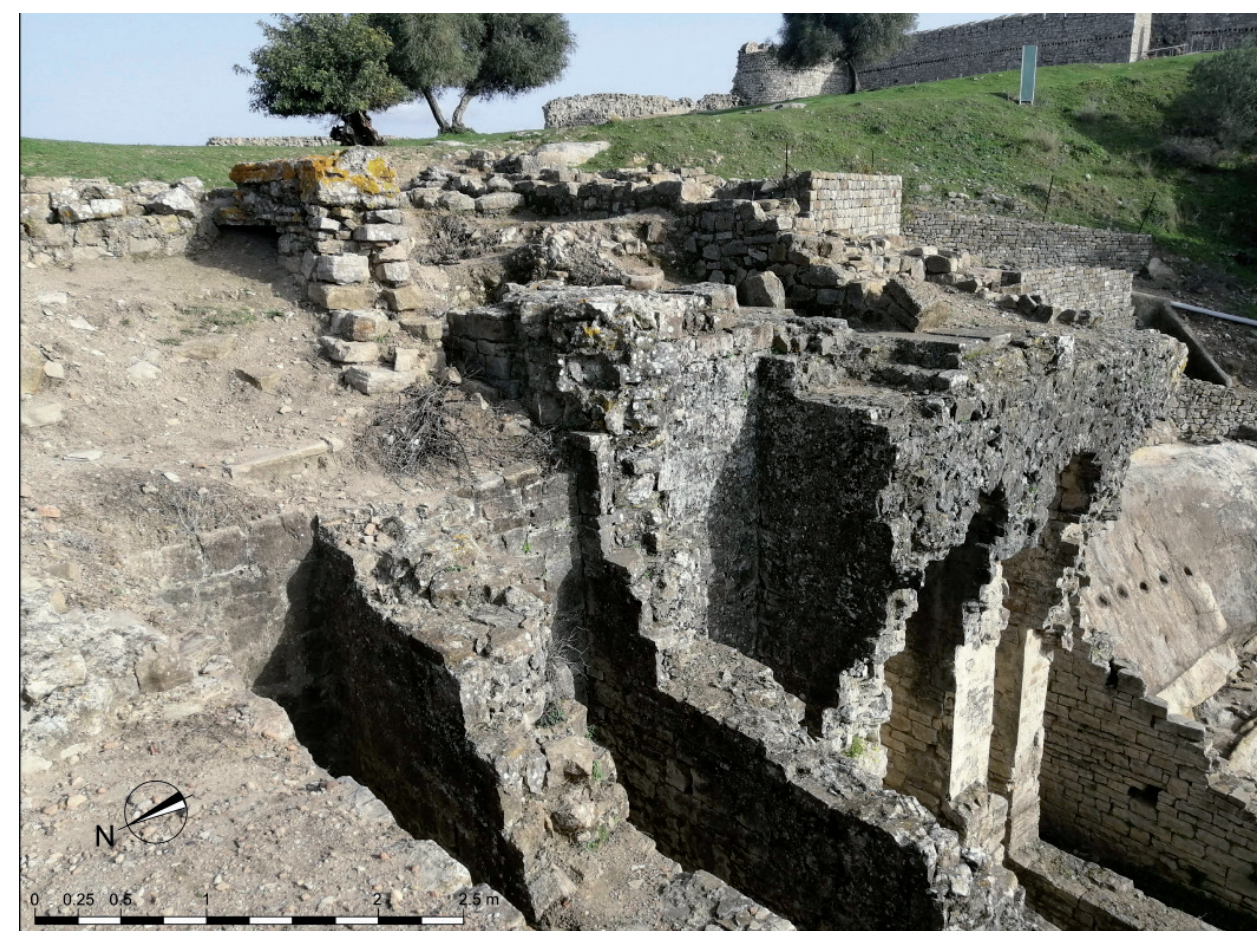

Figura 17. Detalle de las galerías centrales al este, donde se aprecian los muros de las compartimentaciones sin cubierta y con un alzado superior al de los tramos laterales abovedados.

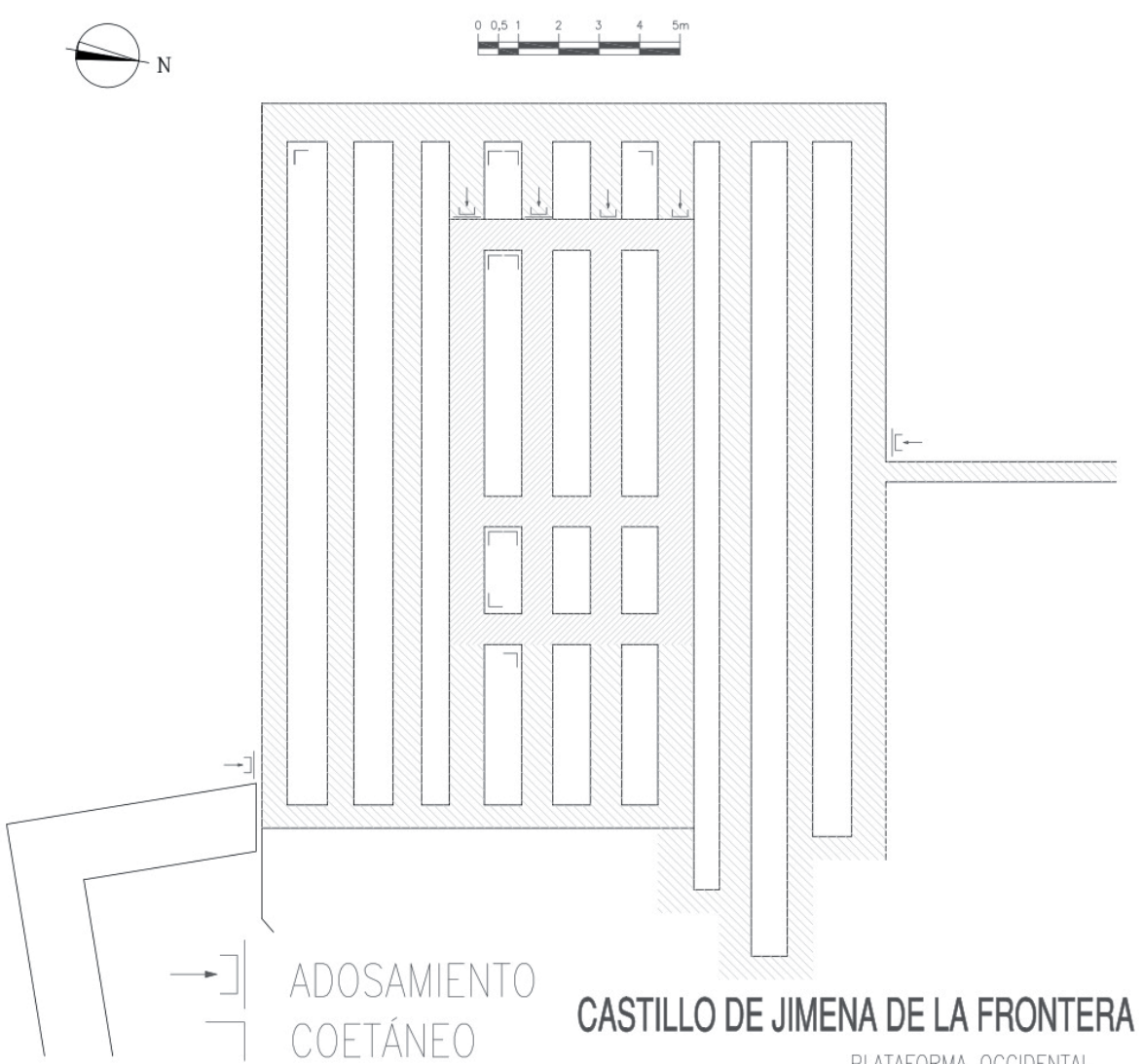

Figura 18. Plano de planta con sistemas de contactos entre los lienzos. 
al muro perpendicular más occidental (fig. 18), formando pequeñas compartimentaciones con unas medidas de $1.82 / 1.87 \mathrm{~m}$ por $0.9 / 0.95 \mathrm{~m}$, refiriéndose Hamo Sassoon a una de ellas como "pozo" (Hamo Sassoon 2001: 142), por la estrechez y profundidad que alcanza - galería 11-, pues parte de la zona más baja de la edificación. Este tramo, actualmente cerrado con una reja, no se encuentra colmatado como los otros dos, posiblemente debido a que su estructura completa debió conservarse intacta más tiempo.

La línea de adosamiento se observa claramente en las tres galerías centrales (fig. 20), aunque es más evidente en la galería 3, que fue completamente excavada y se puede ver el alzado completo del adosamiento desde la roca natural hacia la zona más elevada conservada (fig. 21). Esta unión simple ha sido la que, una vez perdida la zona superior de la estructura, ha provocado el desplazamiento de los muros y bóvedas septentrionales hacia el oeste. Hoy día estos muros se encuentran reforzados con tirantes metálicos aplicados durante la restauración.

En cuanto a las medidas de las galerías laterales, hay una relación clara entre las septentrionales y las meridionales en la anchura de las mismas y de sus lienzos, de tal forma que las dos galerías laterales más cercanas a la edificación central -galerías 3 y 7-, eran más estrechas ( $0.7 \mathrm{~m}$ al norte y 0.78 al sur) y sus lienzos más anchos muros 4 y 9 (0.71 y $0.74 \mathrm{~m}$ )-, aumentando la luz de las galerías a medida que se alejaban de la zona central. Los muros de fachada lateral miden $0.73 \mathrm{~m}$-muros 2 y $11-$. La primera galería de cada extremo mide en torno a 1 metro -galerías 1 y 9-, los segundos lienzos paralelos a la fachada tienen unos $0.6 \mathrm{~m}$-muros 3 y 10 -; las segundas galerías miden 0.97 y $0.99 \mathrm{~m}$ respectivamente - galerías 2 y 8-. Este sistema permitía reforzar la estructura central, ya que es en esas bóvedas donde realmente se produce el contacto de las dos estructuras.

Los mechinales de piedra se aprecian sobre todo en el interior de las bóvedas. Es muy interesante que en las tres galerías septentrionales se emplearan mechinales oblicuos en diferentes muros que están conectados en altura y posición, por lo que se deduce que las vigas de madera dispuestas en sentido diagonal fueron aprovechadas para el andamiaje en la construcción de diferentes galerías a la vez (fig. 22); algo lógico, debido a la escasa anchura de estas galerías. En los alzados interiores se han registrado también pequeñas piedras que sobresalen del aparejo intencionadamente y que debieron cumplir alguna función de sustento o apoyo durante el proceso de construcción.

Con respecto al mortero empleado en la construcción de los muros, se realizó un estudio llevado a cabo

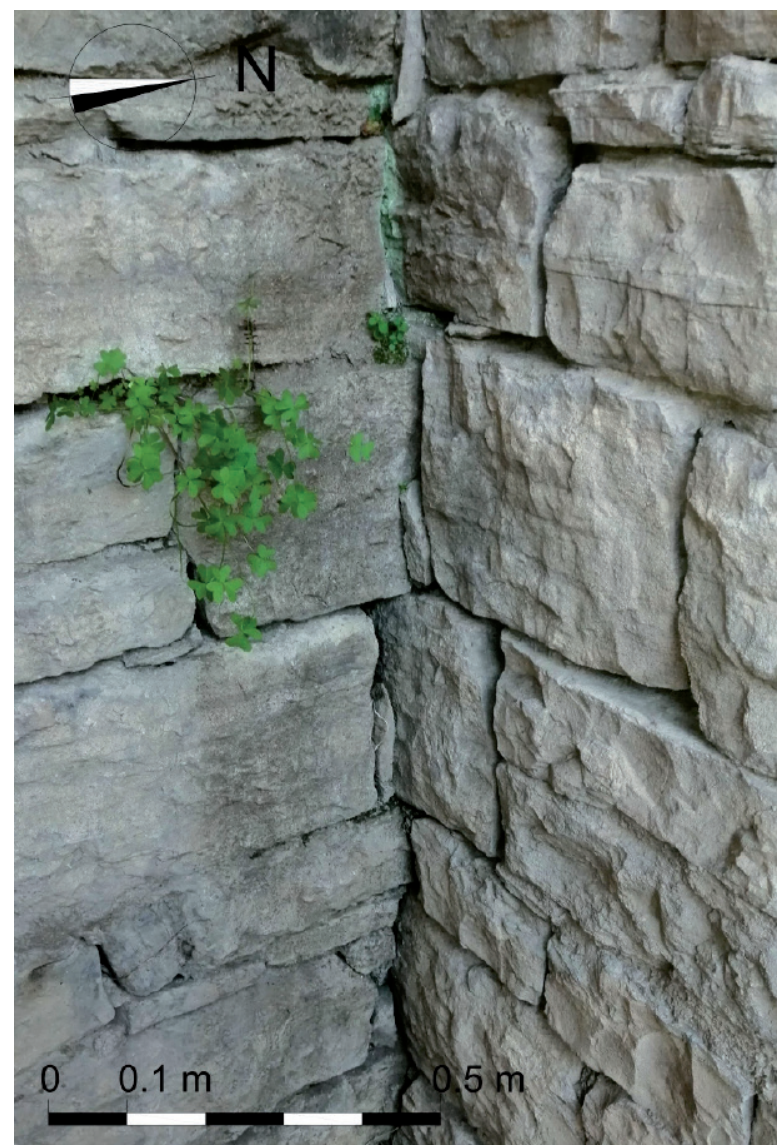

Figura 19. Detalle del encastre entre la fachada oeste y uno de los pequeños muros que se adosa al muro perpendicular occidental.

por Javier Alejandre y J.J. Martín del Río en el que se tomaron muestras y se realizaron analíticas, llegándose a la conclusión de que era un mortero de cal de muy buena calidad y en buen estado de conservación, constituido por carbonato cálcico y arena silícea o cuarzo. Además revelaba que el mortero original contenía un $19.6 \%$ de cal apagada, sin presencia de adiciones puzolánicas ni cerámica triturada -chamota- que le pudieran conferir características hidráulicas.

La última fase correspondería al abovedamiento de las galerías laterales y de los pequeños tramos adosados a las galerías centrales, para generar la superficie plana alrededor de la construcción central, que se elevaría por encima del resto de la construcción (fig. 23, fase III). Con respecto a esta edificación, en la zona superior de la plataforma, entre el trasdós de la galería 3 y uno de estos muros más altos -muro 6-, se descubrió en la intervención del año 2002 (Tabales et al. 2005: 141) parte de una estructura de desagüe y una sucesión 


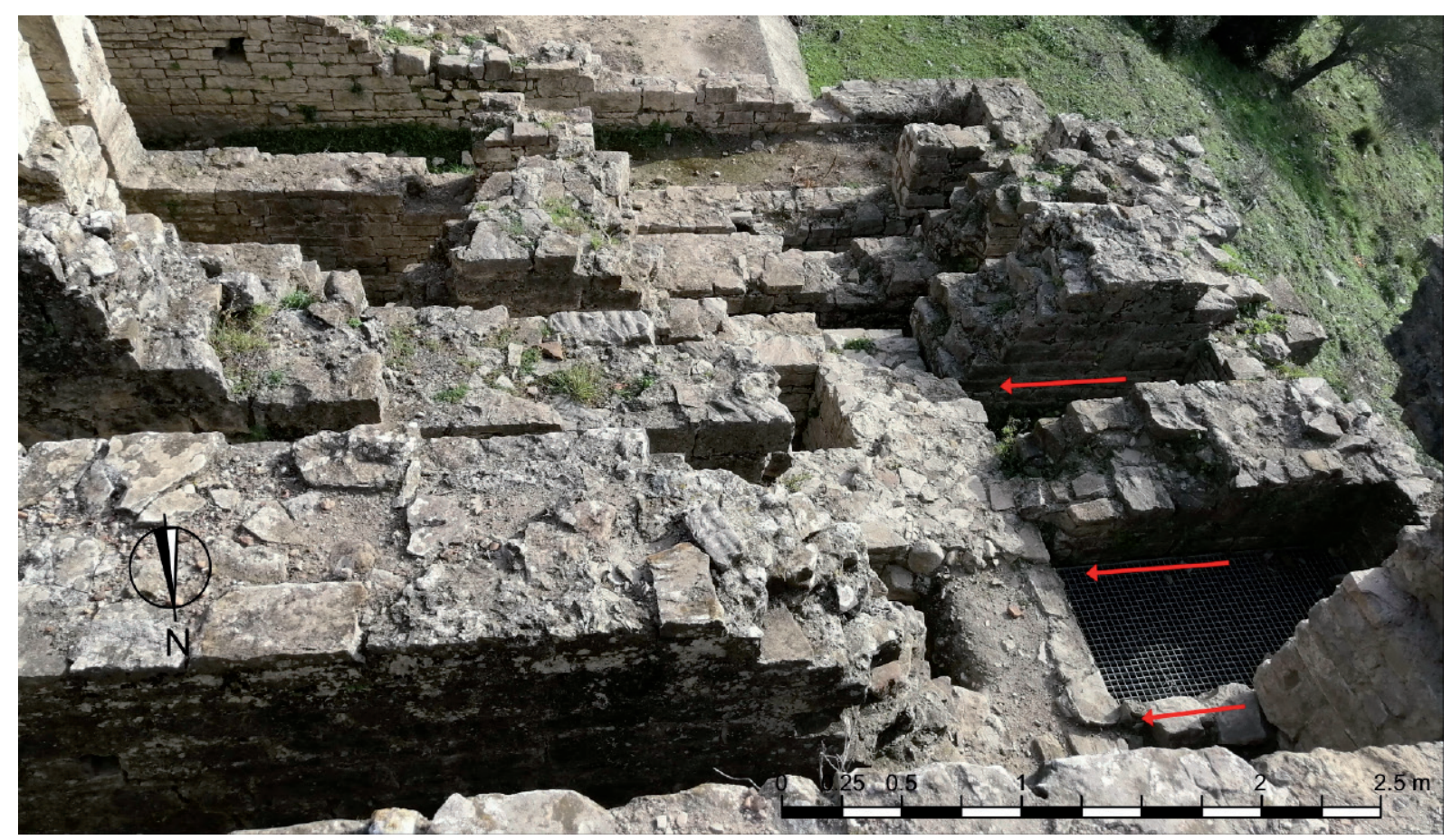

Figura 20. Zona occidental de la plataforma con detalle del adosamiento de los pequeños muros laterales al muro perpendicular occidental.

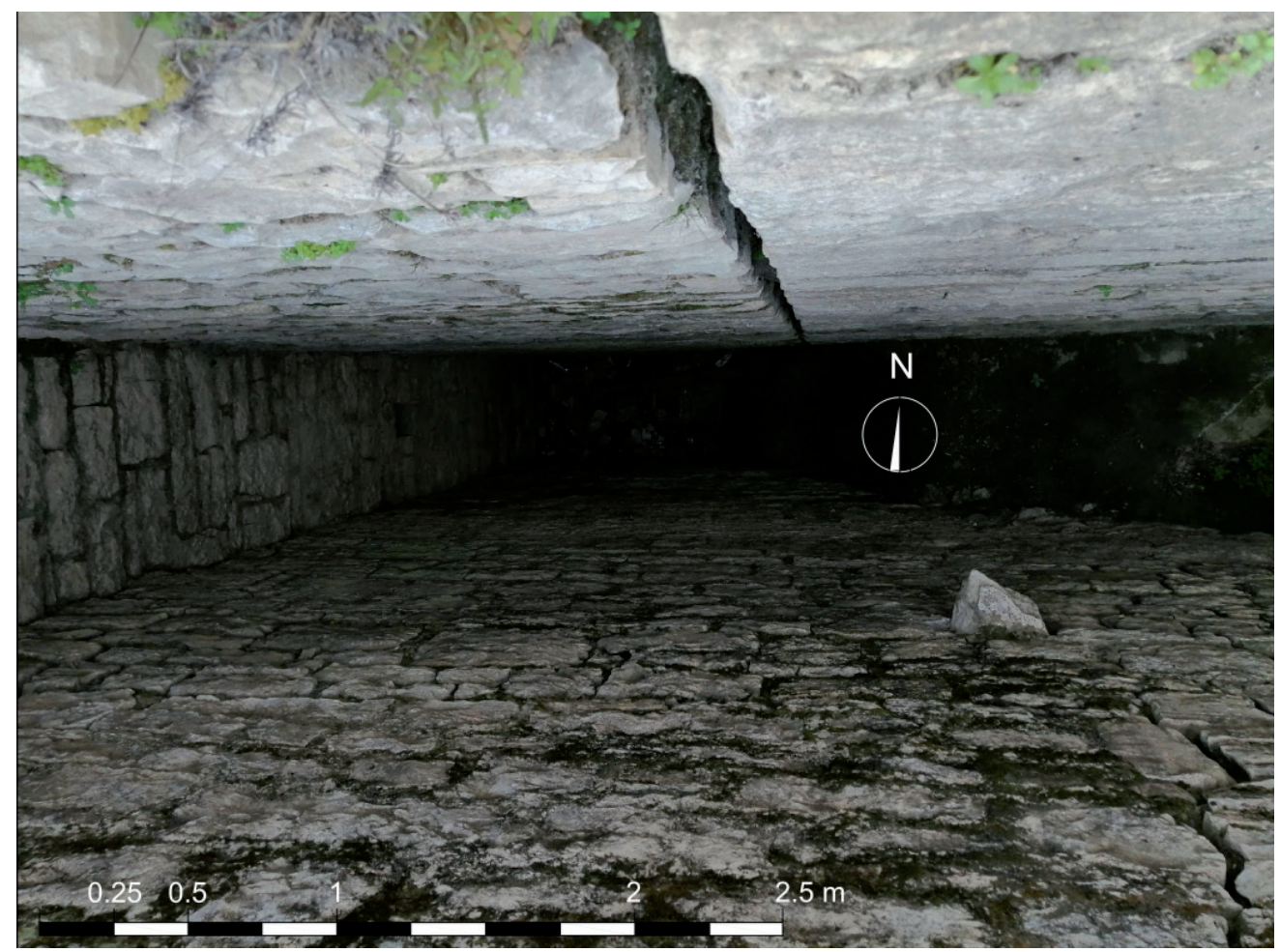

Figura 21. Imagen de la galería 3 excavada, en la que se puede observar el interfaz de adosamiento de los pequeños muros trabados con la fachada al muro meridional de la estructura central. En el lienzo paralelo continuo, se aprecia una de las pequeñas piedras que sobresalen del aparejo. 


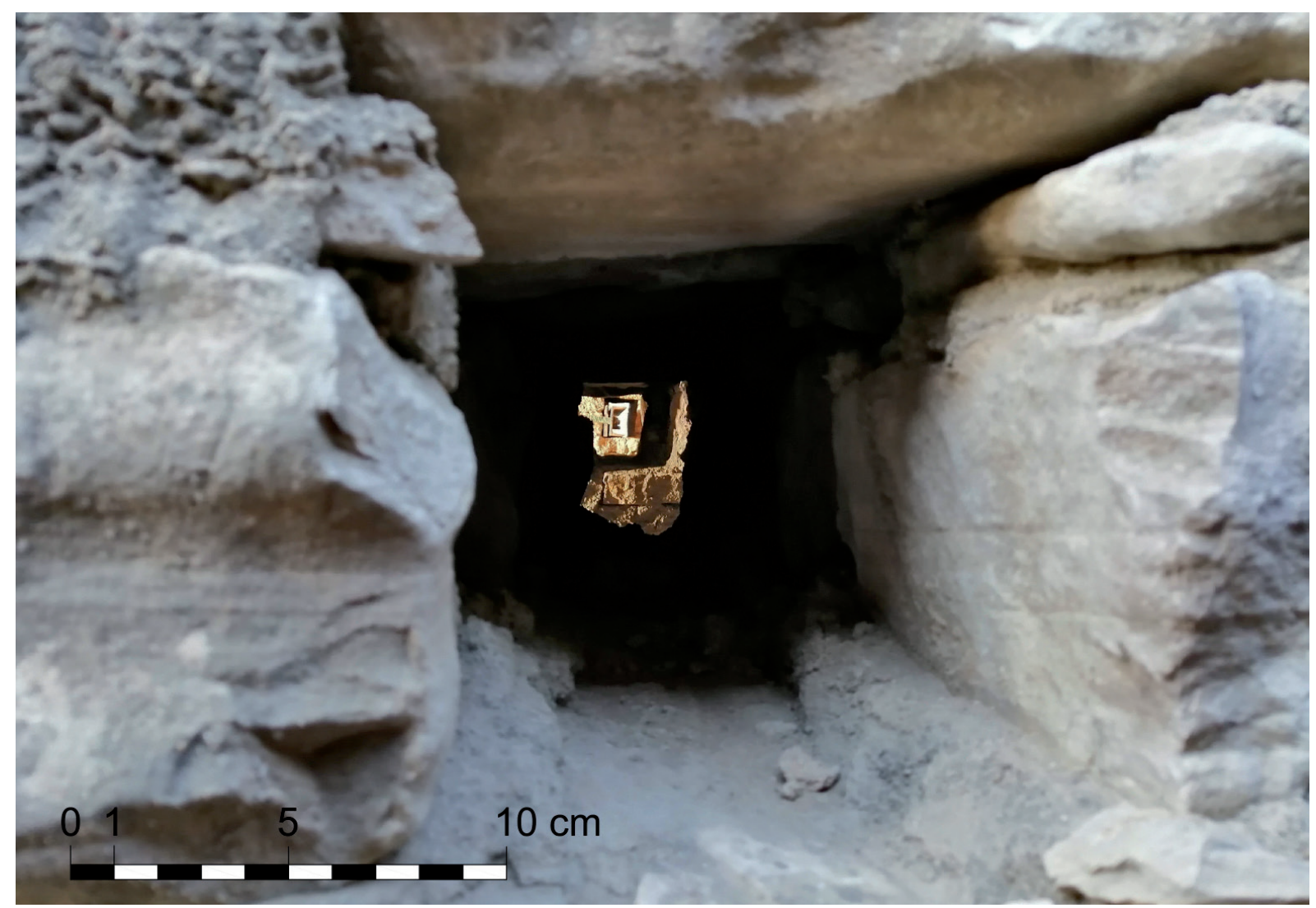

Figura 22. Mechinal oblicuo con conexión con otros mechinales en los lienzos paralelos.

de tres molduras con una longitud de $1.32 \mathrm{~m}$ (figs. 24 y 25). La canalización está formada por losas de piedra caliza con media caña en su centro y tiene un recorrido total de $2.9 \mathrm{~m}$. Las molduras son cóncavas con perfil de cuarto de círculo - caveto- y constituyeron el inicio de la edificación más alta, un podium que por definición formaría parte de un templo (Tabales et al. 2005: 141).

Esta edificación sería la que ocuparía el espacio de las tres galerías centrales del cubo, los muros perpendiculares sobre los que apoyaría determinarían su planta, con la ubicación del pórtico y de la cella, cuya entrada se situaría hacia levante. El ejemplo más cercano está en los tradicionalmente denominados templos del capitolio de Baelo Claudia, aunque las hipótesis más recientes argumentan una adscripción al culto de los dioses originarios de la ciudad de origen púnico (Bendala, 2016: 35) y aluden a que la singularidad de los mismos es "la expresión, seguramente, de una relectura de la tipología templaria propia de las ciudades púnicas con ropaje arquitectónico romano" (Bendala, 2016: 28). El conjunto se dató en el siglo I d.C. (Sillières, 1997: 87-95), concretamente el autor establece la fecha sobre el año 65 para la "instalación de los suelos en los templos terminando, con ello, la edificación del gran santuario capitolino" (Sillières, 2016: 111-113). Se encuentran en una terraza al norte del foro y son tres templos con idéntica morfología: tetrástilos y pseudoperípteros (Sillières, 1997: 91).

En el caso del edificio jimenato de menor monumentalidad, las dimensiones vendrían delimitadas por los muros transversales del interior de la plataforma. La anchura sería de unos $6 \mathrm{~m}$ por al menos $10.54 \mathrm{~m}$ de largo, aunque no podemos descartar que esta última sea mayor, si añadimos una escalinata de acceso que no necesitaría un refuerzo de sustentación. Son por tanto estructuras rectangulares a las que se accede únicamente por el frontal mediante escalinata, ante ella se situaría un pórtico tetrástilo o pareado -in antis-. El ámbito interior se articulaba mediante un paramento con vano central en dos salas. Exteriormente presentaban pilastras como única molduración de los muros laterales. Con respecto a los elementos constructivos que lo componían, en los alrededores de la plataforma se han podido recuperar algunos que se encontraban en superficie y que pudieron formar parte de la edificación, aunque la mayoría de ellos deben de estar 


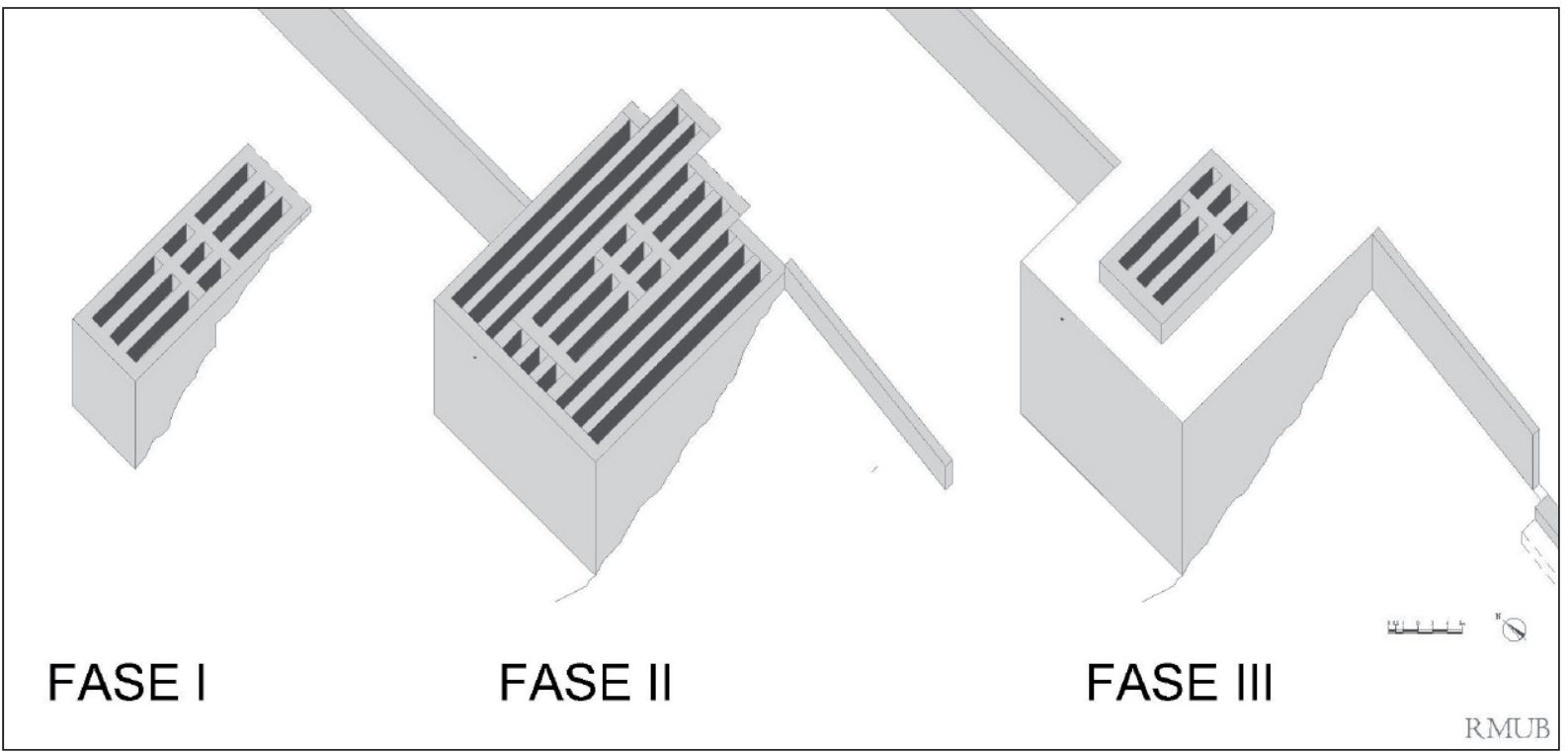

Figura 23. Plano de hipótesis con las fases de construcción de la plataforma.

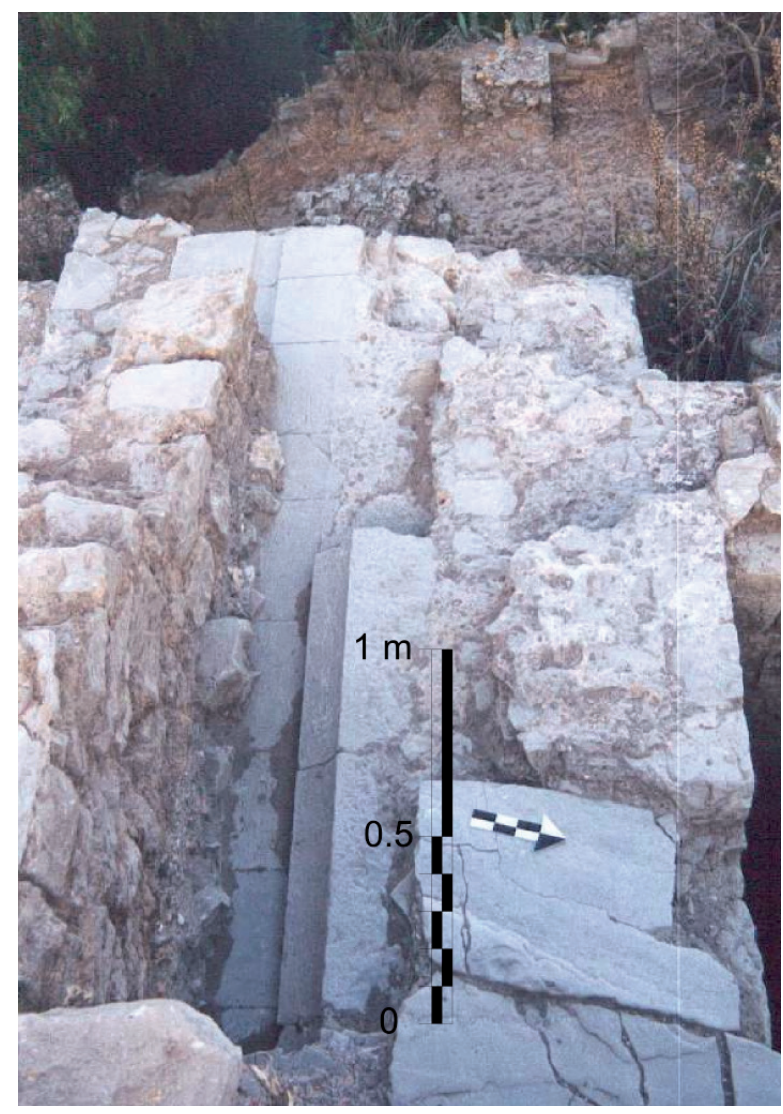

Figura 24. Canalización de desagüe e inicio de la moldura del podium de la edificación. Nótese como la moldura comienza justo en el lienzo que delimita la edificación central al sur (muro 8, galería 13). soterrados en la ladera cercana. La escasez de los restos conservados y las escasas intervenciones realizadas hasta la fecha, no nos permiten una descripción más aproximada al templo jimenato, pero podemos hipotetizar que se trataba de un templo tetrástilo próstilo (fig. 26).

Los materiales datantes registrados en los estratos inferiores de los pasillos excavados (galerías 3, 4 y 5) han sido muy escasos, pero nos indican una cronología post quem de estos rellenos del siglo I d.C. (fig. 27). La colmatación definitiva de la estructura se realizó en época bajomedieval islámica (siglo XIII-XV).

\section{CONCLUSIONES}

En síntesis, este trabajo se debe considerar como un acercamiento inicial al análisis de la plataforma fundamentado en las intervenciones que se han realizado hasta ahora. El estudio de la estructura ha venido a confirmar su finalidad como cimentación de una edificación superpuesta. Su proceso constructivo y los muros conservados confirman que el espacio central, delimitado por los muros perpendiculares, se constituyó como base real del edificio. La aparición justo en esa zona más elevada de una canalización sobre losas y la basa moldurada del basamento nos lleva a considerar que se trataba del podium y su morfología, la de un templo. Su planta, dibujada por el trazado de esos lienzos, correspondería a un templo tetrástilo próstilo. $\mathrm{Su}$ aspecto sería el de una gran terraza pavimentada sobre 


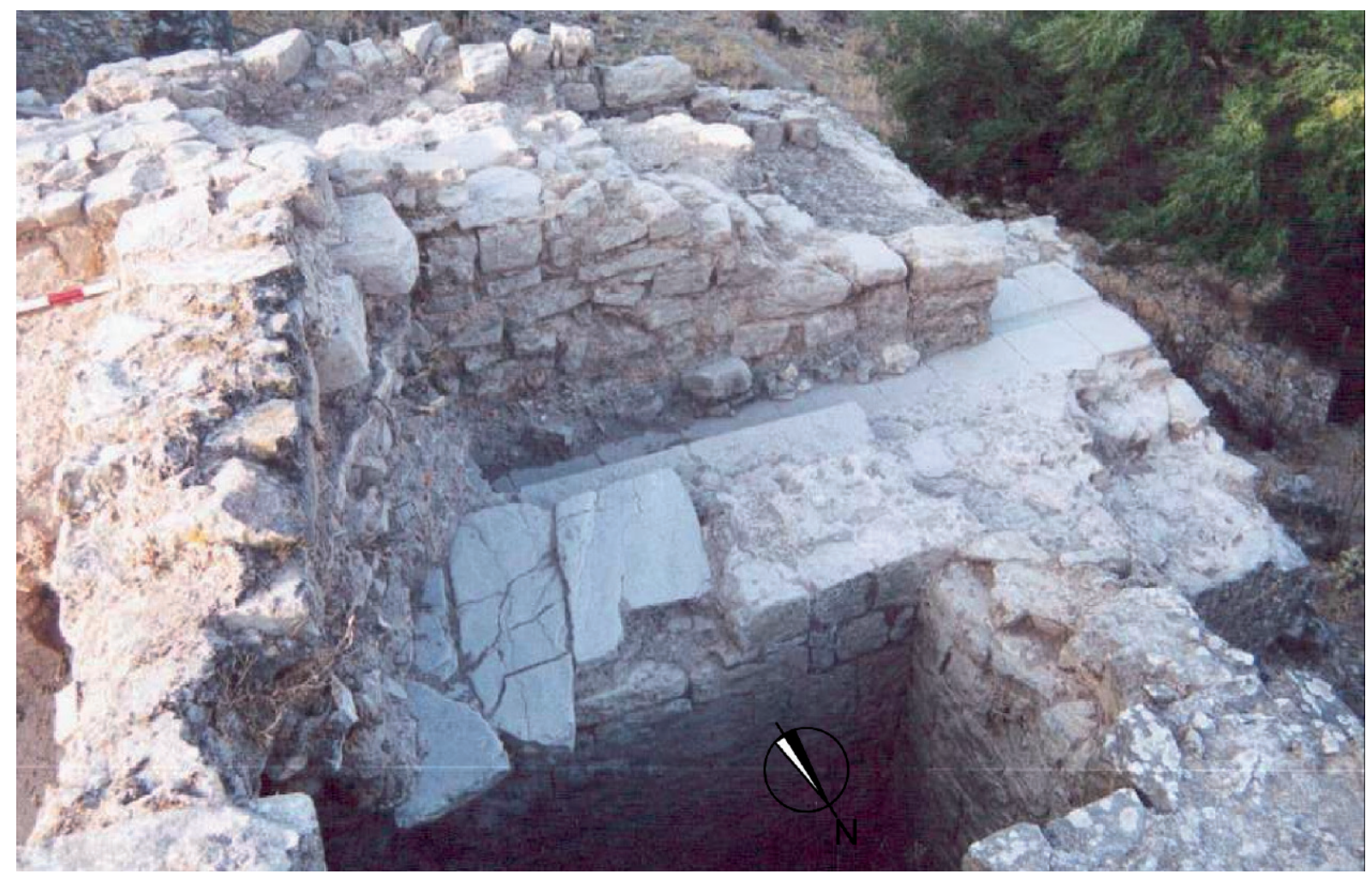

Figura 25. Otra perspectiva del podium con las losas de época posterior sobre la moldura.

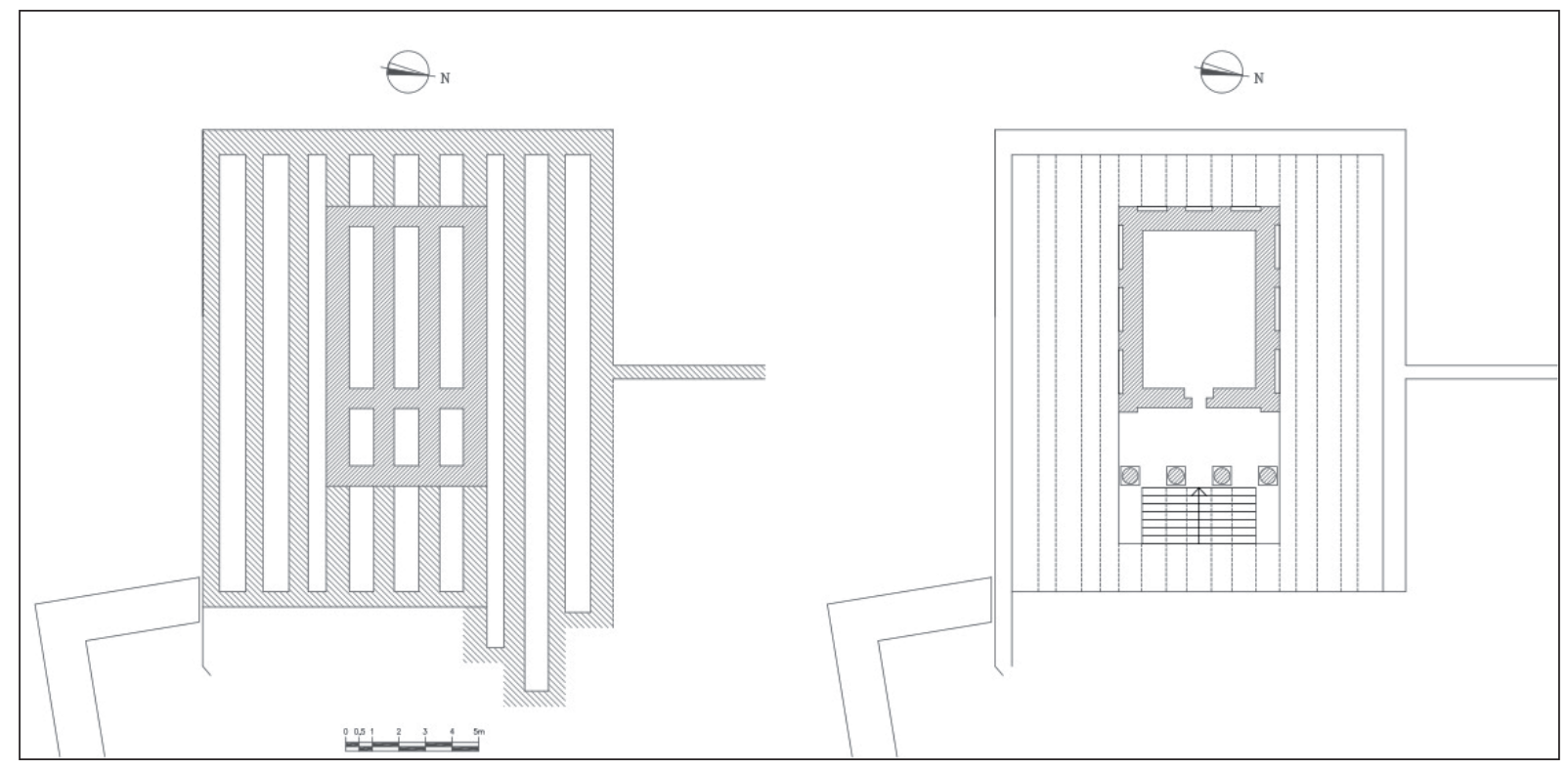

Figura 26. Planta del basamento y ubicación hipotética del templo. 


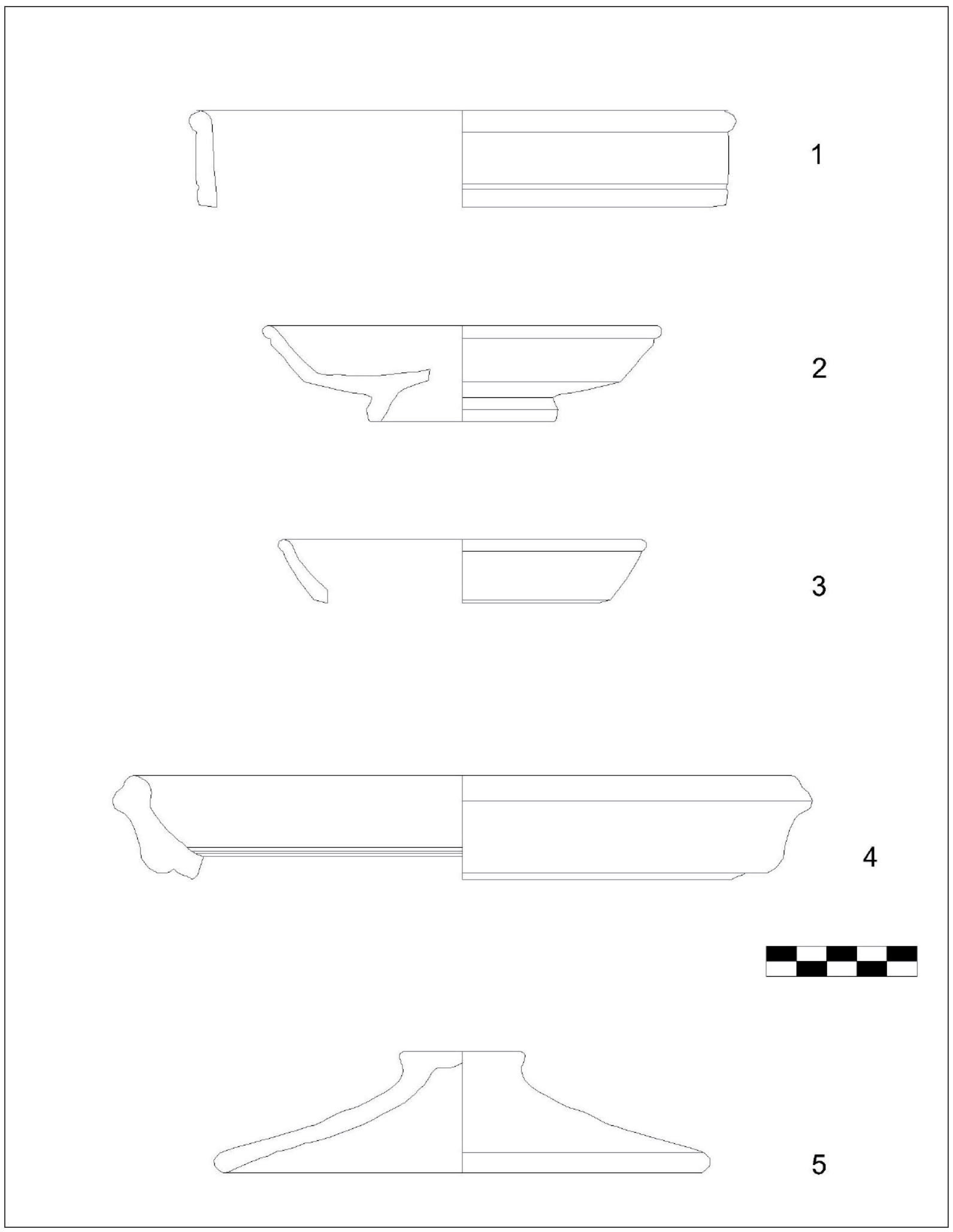

Figura 27. Materiales del relleno de bóvedas. Los tres primeros son TSG, uno de la forma Drag. 37 y dos Drag. 18. Los últimos corresponden a cerámicas comunes, mortero (4) y tapadera (5). 


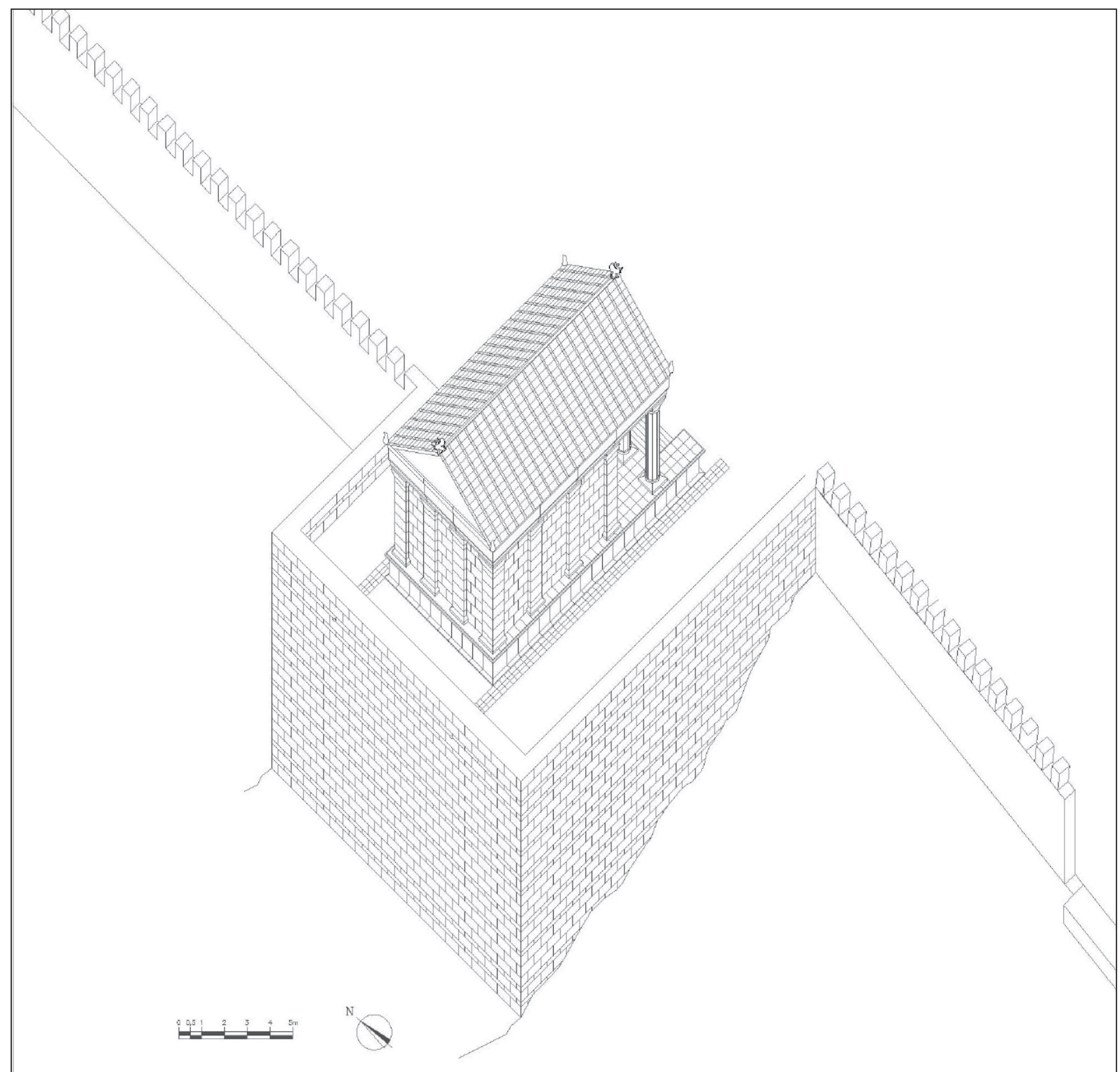

Figura 28. Reconstrucción hipotética de la plataforma de sustentación y del templo de la ciudad de Oba, con la zona donde se situaba la puerta occidental.

la que predominaba el templo en su parte central, con unas proporciones totales que destacarían desde cualquier punto del entorno y muy próxima a la puerta occidental de la ciudad (fig. 28). Su situación sobreelevada y destacada recuerda a otras construcciones cultuales conocidas en la Bética como el santuario de Munigua, construido sobre terrazas artificiales que dominaban la colina sobre la que se asentaba la ciudad (Hauschild, 1991: 135-138), o el templo sobre el denominado bastión en la puerta de Sevilla en Carmona (Jiménez Martín 1989: 194-195), sobre la que se ha expuesto que el complejo arquitectónico tuvo como principal objetivo proporcionar una plataforma en alto para un templo (Schattner 2005). Las investigaciones sobre la Puerta de Carmona han presentado paralelos muy interesantes, destacando el Avancorpo de la acrópolis de Ferentinum, un cubo sobresaliente de la muralla que sirvió como base de un edificio construido sobre él (Schattner 2005: 84-85, Jiménez Martín 1989: 194)

La excavación arqueológica de algunas de las galerías y el hecho de que todavía existan bóvedas sin documentar bajo el subsuelo o que sean prácticamente 


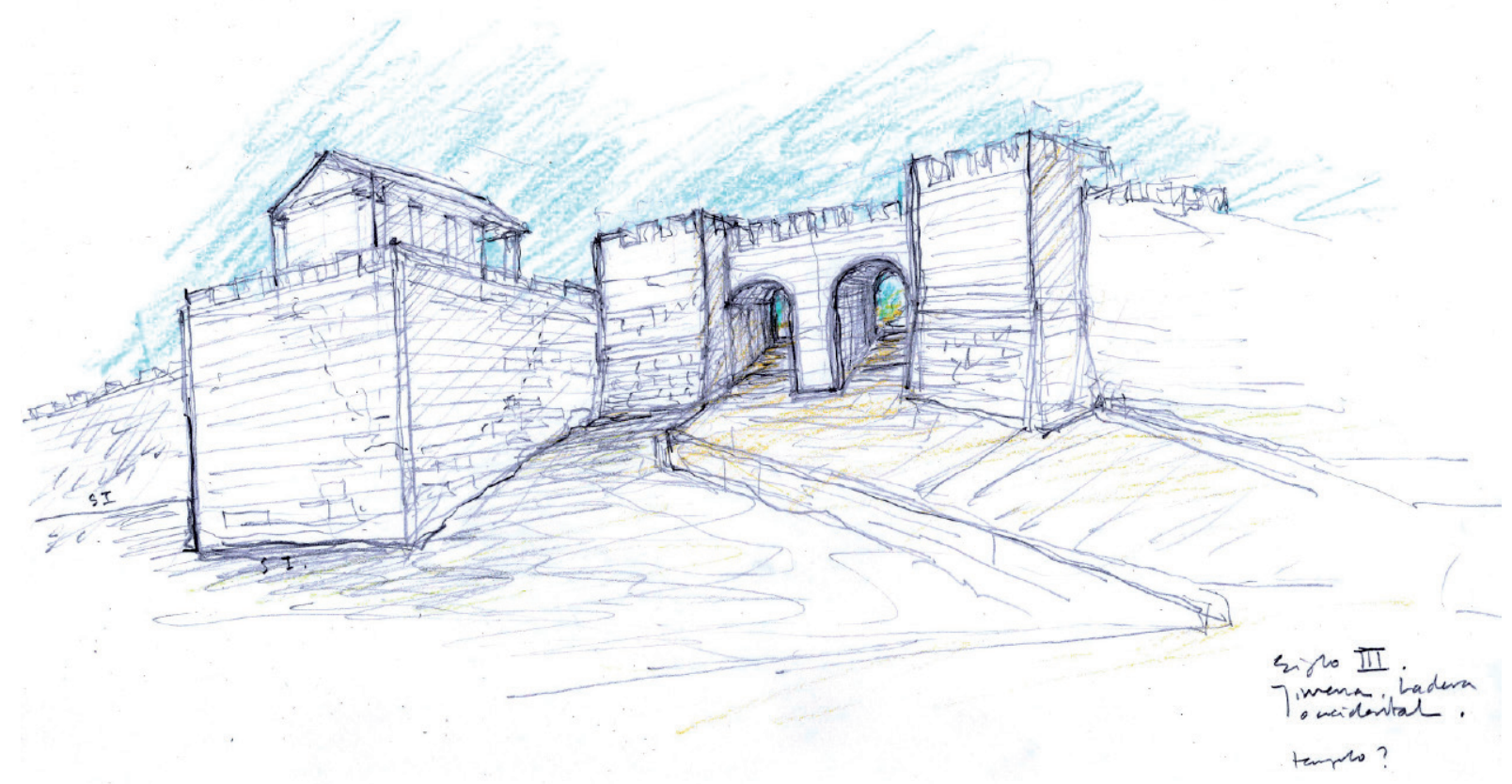

Figura 29. Reconstrucción hipotética de la muralla occidental con la puerta de la ciudad y el templo en el siglo III d. C. (Autor: Francisco Reina, arquitecto coordinador de los proyectos de restauración).

inaccesibles -galería 14-, nos permiten deducir que no tuvieron ningún otro fin que el de basamento adaptado al desnivel del terreno, ya que estaban incomunicadas, determinándose su colmatación y reutilización a partir del período bajomedieval. No podemos, sin embargo descartar que existiera algún tipo de comunicación entre la zona central de la plataforma y el templo.

El análisis constructivo de los aparejos y los materiales registrados hasta la fecha indican una cronología del siglo I a.C.-I d.C., momento de mayor prosperidad de la ciudad. La construcción del templo y su plataforma de cimentación formaron parte de la primera etapa de ordenación urbana de la ciudad romana, una planificación general del amurallamiento y de las edificaciones civiles más importantes, lo que queda patente en el hecho de que la plataforma de cimentación se edifica antes que la muralla occidental, que se le adosa. Que en ambas construcciones se empleen fábricas vistas con aparejos muy cuidados y el mismo dato de la erección primigenia del templo, apuntan hacia una intencionalidad propagandística más que militar, algo que se confirma también en las primeras construcciones romanas de la ladera oriental. Se trata de aplicar el proceso de romanización a la ciudad y su territorio a través de la construcción de edificaciones de prestigio, destinadas en primera instancia a impresionar a la población autóctona y en menor grado, a realizar una defensa efectiva.

La transformación del edificio debió comenzar entre los siglos II y III d.C., motivada tal vez por el peligro de las invasiones de los pueblos mauritanos procedentes del norte de África, que si bien no parece que afectaran a la Oba clásica, su amenaza sí pudo potenciar este cambio urbano. En esos momentos se produjo una reorganización del sector del acceso a la ciudad, de tal forma que la terraza superior se transformó en un espacio diáfano relacionado con el refuerzo de la puerta occidental, a través del adosamiento de un gran bastión defensivo junto a la estructura (fig. 29). Este refuerzo se ha constatado también en la zona oriental de la ciudad.

Su colmatación y definitiva simplificación se produjo en época islámica, durante los siglos XIII al XV, momento tras el cual se documenta un uso efectivo de los espacios interiores de la plataforma, mediante la apertura de huecos en las bóvedas para facilitar la comunicación de las diferentes galerías. El deterioro de la estructura continuó hasta inicios del siglo XXI, cuando se comenzaron a realizar las primeras actuaciones de restauración e investigación en las murallas del castillo.

A pesar de las excavaciones realizadas y de las consolidaciones básicas llevadas a cabo durante la última década, quedan muchas cuestiones no resueltas, entre 
ellas su adscripción. El análisis arqueológico integral y su definitiva restauración son una asignatura pendiente que esperamos se solvente lo antes posible.

\section{Agradecimientos}

Este trabajo se encuadra dentro del grupo investigación TEP-211 (Construcción Patrimonial) de la Junta de Andalucía.

Queremos agradecer a $\mathrm{M}^{\mathrm{a}}$ Isabel Gómez Arroquia el estudio de los materiales datantes de época romana de la plataforma. También agradecer y destacar el trabajo de los compañeros de la primera campaña de intervención que asentaron las bases de las actuaciones posteriores y por supuesto, de este trabajo: Pablo Oliva Muñoz, Gregorio Mora-Vicente, Rosario Huarte Cambra, Amparo Graciani, José María Calama Rodríguez y Arturo Pérez Plaza. Las investigaciones fueron financiadas por la Dirección General de Bienes Culturales de la Junta de Andalucía. BIBLIOGRAFÍA

\section{Abreviaturas}

CIL II: Hübner, E., (1869): Corpus Inscriptionum Latinorum II. Inscriptiones Hispaniae Latinae, Berlín.

IRPCA: González Fernández, J. (1982): Inscripciones romanas de la provincia de Cádiz. Cádiz, Diputación Provincial.

Bendala Galán, M. (2016): “La caracterización del paisaje urbano: el caso de Baelo Claudia", en Actas de las II Jornadas Internacionales de Baelo Claudia. Nuevas investigaciones, Cádiz/Baelo Claudia (14 y 15 abril 2010), Junta de Andalucía, Consejería de Cultura.

Carretero Poblete, P.A. (2008): “Arqueología toponímica: traslación de algunos topónimos norteafricanos a Turdetania”, en González, J., Ruggeri, P., Vismara, C. y Zucca, R.: L'Africa Romana: Le ricchezze dell'Africa. Risorce, produzioni, scambi, 2. (Sevilla, 2006):13331340. Roma, Pubblicazioni del Centro di Studi Interdisciplinari sulle Province Romane dell'Università degli Studi di Sassari, Consejería de Cultura de la Junta de Andalucía y Universidad de Sevilla.

García Díaz, M.; Gómez Arroquia, Mª I.; Mariscal Rivera, D. y Torres Abril, F. (2003): "Resultados del proyecto de investigación: realización de la catalogación genérica y colectiva del inventario de yacimientos arqueológicos. Campo de Gibraltar". Almoraima 29: 43-57.
Hauschild T. (1991): "Los templos romanos de Munigua (Sevilla)". Templos romanos de Hispania. Cuadernos de Arquitectura Romana, Vol.1: 133-143.

Huarte Cambra, R. (2005): “Análisis histórico-estratigráfico de los materiales cerámicos del castillo de Jimena de la Frontera (Cádiz)", Anuario Arqueológico de Andalucía 2002, III, vol. 1: 119-130.

Jiménez Martín, A. (1989): La Puerta de Sevilla en Carmona, Sevilla. Sevilla, Junta de Andalucía, Consejería de Obras Públicas y Transportes.

Regueira Ramos, J.; Regueira Mauriz, E. y Mena Torres, M. (1988): Jimena y su Castillo. Cádiz, Alba Editorial.

Reina Fernández-Trujillo, F. y Tabales Rodríguez, M. (2006): "Castillo de Jimena de la Frontera: descripción de una estrategia de intervención". PH 60, Boletín del Instituto Andaluz del Patrimonio Histórico, 60: 152-169. https://doi.org/10.33349/2006.60.2268

Romero de Torres, E. (1934): Catálogo monumental de España. Provincia de Cádiz (1908-1909). Madrid, Ministerio de Instrucción Pública y Bellas Artes.

Sassoon, H. (2001): "Romanos y moros en las afueras del castillo de Jimena: nuevos descubrimientos". Almoraima 25: 141-148.

Schattner T.G. (2005): La Puerta de Sevilla en Carmona y otras puertas romanas en la Península Ibérica. Rómula 4: 67-98.

Sillières, P. (1997): Baelo Claudia, una ciudad romana de la Bética. Madrid, Casa de Velázquez.

Sillières, P. (2016): "La datación de los grandes monumentos de Baelo Claudia. Aportación de los sondeos estratigráficos", en Actas de las II Jornadas Internacionales de Baelo Claudia. Nuevas investigaciones. Cádiz/Baelo Claudia (2010), Junta de Andalucía, Consejería de Cultura.

Tabales Rodríguez M.A. (2002): Sistema de análisis arqueológico de edificios históricos. Sevilla, Instituto Universitario de Ciencias de la Construcción, Universidad de Sevilla.

Tabales Rodríguez M.A. (2006): "Programa de investigaciones arqueológicas en el castillo de Jimena de la Frontera". Almoraima 33: 9-30.

Tabales Rodríguez, M.A; Oliva Muñoz P.; Mora-Vicente G.; Huarte Cambra R.; Graciani A.; Calama Rodríguez J.Ma . y Pérez Plaza A., (2005): "Investigaciones arqueológicas en el castillo de Jimena de la Frontera. Fase I (2002)", Anuario Arqueológico de Andalucía, III, vol. 1 (2002): 131-155.

Villaronga Garrigues, L. (1994): Corpus nummun Hispaniae ante Augusti aetatem. Madrid, Ed. José A. Herrero. 
